\title{
Molecular Complexes for Effective Inhibition of Tau Aggregation
}

\author{
Nalini V. Gorantla, ${ }^{[a],[c]}$ Vinod G. Landge,${ }^{[b],[c]}$ Pramod G. Nagaraju, ${ }^{[c],[d]}$ Lisni P. Sunny, ${ }^{[a]}$ Anjhu \\ Nair, ${ }^{[a]}$ Siba P. Midya, ${ }^{[b],[c]}$ Poornima Priyadarshini CG, ${ }^{[c],[d]}$ Ekambaram Balaraman, ${ }^{*[b],[c]}$ and \\ Subashchandrabose Chinnathambi ${ }^{* *},[\mathrm{a}],[\mathrm{c}]$
}

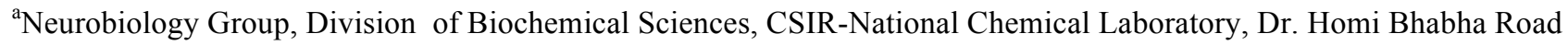
411008 Pune, India

${ }^{\mathrm{b}}$ Catalysis Division, CSIR-National Chemical Laboratory, Dr. Homi Bhabha Road 411008 Pune, India.

${ }^{\mathrm{c}}$ Academy of Scientific and Innovative Research (AcSIR), 110025 New Delhi, India

${ }^{\mathrm{d}}$ Department of Molecular Nutrition, CSIR-CFTRI, 570020 Mysore, India

[**] Corresponding author: Dr. Subashchandrabose Chinnathambi. Email: s.chinnathambi@ncl.res.in
\end{abstract}

Supporting Information

\begin{abstract}
Tau is an axonal protein known to form abnormal aggregates and is the biomarker of Alzheimer's disease. Metal-based therapeutics for inhibition of Tau aggregation is limited and rarely reported in the contemporary science. Here, the first example is reported of a rationally designed molecular cobalt(II)-complexes for effective inhibition of Tau and disaggregation of preformed Tau fibrils. The mechanistic studies revealed that the prevention of Tau aggregation by CBMCs is concentration-dependent and Tau seldom exhibits conformational changes. Interestingly, CBMCs play a dual role by causing disassembly of preformed aggregates as well as complete Tau inhibition. We believe that this unprecedented finding by the newly developed molecular complexes has a potential to lead to developing innovative metal-based therapeutics for Alzheimer's disease.
\end{abstract}

Key words: Tau Protein, Tau aggregation inhibition, Metal based compounds, Alzheimer's disease 


\section{INTRODUCTION}

Alzheimer's disease (AD) is a neurodegenerative disorder characterised by progressive cognitive and behavioural impairment. Worldwide 44 million people are known to have AD and its related dementia. Abnormal protein deposits in the brain, such as extracellular amyloid plaques and intracellular neurofibrillary tangles (NFTs), characterize AD. The microtubule-associated protein Tau (MAPT) plays a key role in several neurodegenerative diseases, like AD, FTDP-17 and Parkinson's disease etc. ${ }^{1}$ The axonal protein Tau is expressed in the adult human brain as six different isoforms. Due to alternative splicing, two N-terminal inserts and the second repeat (R2) in the C-terminal microtubule-binding domain can be present or absent (Fig. 1A). Upon hyperphosphorylation, Tau disassembles from microtubule (MT) and self-assembles to form NFTs which consist of straight paired helical filaments (PHFs). ${ }^{1}$ Several factors are responsible for triggering under pathological conditions, such as post-translational modifications, oxidative stress, truncation, and metal ions etc. ${ }^{3,4}$ Thus, there is an immense interest to identify potentially active molecules derived from metal complexes, natural products, and short-range peptides for inhibition of Tau aggregation or to disaggregate the pre-formed fibrils of Tau. ${ }^{5,6}$ Recently, methylene blue and methylthionine hydrochloride have been identified as inhibitors of Tau aggregation and were subjected to phase III clinical trials. ${ }^{7}$ Indeed, there is a strong need for the discovery of new potential therapeutics. ${ }^{8-9}$ In this regard, significant research is being devoted in recent times to identify active compounds ${ }^{10,11,12,13}$ with novel scaffolds that may have potential properties for the treatment of AD by inhibiting Tau aggregation. ${ }^{14,15}$

Recently, the importance of different metals in the $\mathrm{AD}$ is well studied, which elucidates the critical role of metal ions in pathology. ${ }^{16}$ Metal ions are mostly involved in the physiological functions and they are also known to interact with proteins leading to their aggregation. ${ }^{17,18}$ Metal ions such as copper(II), zinc(II), iron(III) and aluminium(III) are well-studied for their protein aggregation property. It was reported that copper and zinc interact with Amyloid $\beta$ and promote their aggregation. ${ }^{19,20}$ The mode of binding of these metal complexes with Amyloid $\beta$ was studied by Raman spectroscopy and revealed the importance of the three histidines present at the N-terminus. ${ }^{21}$ Later, the role of iron(III) in the aggregation of Amyloid $\beta$ was studied by NMR experiments, which revealed the importance of first 16 amino acids in the formation of iron coordination. ${ }^{22}$ The interaction of copper(II) ions with Tau was analyzed by Soragni et al., by NMR studies, which showed the importance of amino acid sequences 
adjacent to hexapeptide motif in the second and third repeat of Tau. The effect of copper on Tau protein aggregation via. oxidation of cysteine residues was the key interest for copper binding. ${ }^{23}$ In AD brain, Tau hyperphosphorylates and aggregates to form PHFs, ions such as aluminium(III) specifically interact with its phosphorylated epitopes. ${ }^{24}$ These findings suggest that phosphorylated Tau is triggered for aggregation in the presence of aluminium(III). Further, the effect of aluminium maltolate administration was reported for neurodegeneration in rabbits. ${ }^{25}$ However, the effect of zinc(II) on Tau fibrillization in physiological conditions is contradicting to that of copper(II) and aluminium(III). The lower levels or deficiency of zinc(II) would enhance Tau aggregation by decreasing the expression of Tau or by reducing the ability of Tau to interact with MTs. Sequestration of zinc(II) by extracellular senile plaques leads to decreased intracellular zinc levels, which ultimately leads to NFTs formation. Importantly, the presence of higher intracellular zinc levels leads to hyperphosphorylation of Tau at S214, which eventually forms aggregates. ${ }^{26}$ Furthermore, ferric iron can lead to Tau aggregation in vitro, and its reduced form causes hyperphosphorylation of Tau. ${ }^{27,28}$ Other targets of $\mathrm{AD}$ such as acetylcholine esterase and monoamine oxidase are also altered by the levels of metal ions. ${ }^{29}$ Notably, other neurodegenerative diseases like Creutzfeldt Jakob disease are also known to be caused by the presence of unbalanced metal ions. The cellular prion protein $\operatorname{PrP}^{\mathrm{c}}$ undergoes conformational changes to $\operatorname{PrP}^{\mathrm{Sc}}$ and leads to prion disease. Similarly, the pathological conformational changes in the prion protein were observed upon its interaction with copper(II). ${ }^{30}$ The significance of copper interaction with octarepeats in PrP was revealed by using NMR, tryptophan fluorescence emission and Raman spectroscopy. ${ }^{30,31}$

In our present studies, we screened the effect of rationally designed molecular cobalt based metal complexes (CBMCs; Fig. 1B) on Tau aggregation and found that these complexes are effective in preventing the formation of a toxic population of Tau. The CBMCs were effective in inhibiting polymerization of Tau in concentrationdependent manner. The efficacy of these metal complexes were analysed by fluorescence assay, studying the conformational change in Tau by spectroscopic techniques and the morphology of aggregates was observed by microscopic analysis. 


\section{RESULTS AND DISCUSSION}

\section{CBMCs, as a barrier for Tau aggregation}

Tau protein is one of the major microtubule-associated proteins in neuronal axons that mainly functions to stabilize and assemble MTs. ${ }^{32}$ Tau is a soluble protein and adopts natively unfolded structure in solution. ${ }^{33}$ The repeat domains of Tau and the flanking proline-rich regions confers the property of MT binding and assembly (Fig. 1A). The repeat domains of Tau represents the core of PHFs. ${ }^{34}$ The hexapeptide motifs in repeat 2 and 3 form the basic motif for aggregation. In vitro conditions, heparin is used as an inducer to enhance Tau aggregation. ${ }^{34}$ Heparin binds to the positively charged residues of flanking repeats 2 and 3, and thus leading to charge neutralization. Further, the binding of heparin also leads to change in conformation of $\beta$-sheet, which serves as a nucleation centre for the aggregation. Tau protein was diluted in assembly buffer, incubated for the formation of aggregates in presence or absence of CBMCs and the extent of aggregates formation was monitored by ThS. Our interest in metal-based therapeutics in $\mathrm{AD}$ began with the discovery of novel $\mathrm{Co}(\mathrm{II})$ complexes, since cobalt is relatively abundant, and biorelevant. The reaction of the tridentate ligand with $\mathrm{CoCl}_{2}$ in methanol at $65{ }^{\circ} \mathrm{C}$ for 4 hours results the corresponding cobalt-pincer complexes in excellent yields (See ESI, S1-S7). All the complexes were wellcharacterized and the structure of NNN-L2 $\mathrm{CoCl}_{2}$ was confirmed by a single-crystal X-ray diffraction study (Fig. $1 \mathrm{C})$.

The Co(II)-complexes (CBMCs) were incubated with constant Tau concentration of $0.91 \mathrm{mg} \mathrm{mL}^{-1}$, with increasing concentrations of metal complexes $\left(0.01,0.025,0.05\right.$ and $\left.0.1 \mathrm{mg} \mathrm{mL}^{-1}\right)$. The aggregation of full-length Tau with CBMCs at the higher concentration substantially decreased the ThS fluorescence (Fig. 2A, B and C), which indicates the prevention of aggregates formation. Further, we have quantified inhibition, which revealed that L2 is more potent with $92.5 \%$ inhibition at the lowest concentrations of $0.025 \mathrm{mg} \mathrm{mL}^{-1}$, whereas, $\mathrm{L} 3$ and $\mathrm{L} 1$ showed 85.5 and $73.9 \%$ inhibition, respectively. At the highest concentration of $0.1 \mathrm{mg} \mathrm{mL}^{-1}$, they showed up to $93 \%$ inhibition (Fig. 2D). The higher order species formed upon Tau aggregation were observed by SDS-PAGE analysis (Fig. 2E, F and G). In presence of metal complexes, Tau was able to form higher order aggregates which completely faded away over the time. At 0 hour the intensity of Tau was high which decreased with increasing complex concentration (Fig. 2H). This data is in agreement with the size-exclusion chromatography analysis which is evidenced by the 
retention volume that metal complexes prevent the aggregation of Tau to higher molecular weight species in vitro (Fig. S12A, B, C and D).

\section{Native conformation of Tau maintained by CBMCs}

The changes in Tau conformation due to metal complexes were studied by CD spectroscopy. Tau has no secondary structure and exists as a random coil protein, which absorbs around $190 \mathrm{~nm}$. The aggregated Tau shows a shift towards the higher wavelength, which signifies the transition of the random coil to $\beta$-sheet conformation. In the presence of CBMCs, the typical random coil conformation of full-length (Fig. 3A, B and C) was not altered. These results signify the effect of these complexes in preventing aggregates formation. Tau protein in vitro forms fibrillar morphology in the presence of heparin, which is observed as a long filamentous structure. The extent of aggregate formation by Tau in presence of L1, L2 and L3 were studied by Transmission electron microscopy (TEM), which discloses the vigour of the CBMCs in completely preventing the aggregates formation (Fig. 3D, E, F and G). Further, the EDAX (Energy Dispersive X-Ray) revealed that the negligible amount of CBMCs was associated with Tau, which denotes that Tau was devoid of conjugation with CBMCs (data not shown). X-ray photon electron spectroscopy analysis showed that the oxidation state of the CBMCs remains unchanged during Tau aggregation (data not shown). The formation of higher order species by full-length Tau at 0 hour in presence of CBMCs stimulated us to study its role on soluble Tau. However, surprisingly no higher order aggregates were observed upon incubation at $37{ }^{\circ} \mathrm{C}$ (Fig. S9A) and this manifests the inability of the complexes to form toxic Tau species when compared with the control (Fig. S9B). The initial Tau conformation plays a critical role in order to form the nucleus, which further accelerates the formation of aggregates. Here, we show that these molecular Co(II)complexes did not induce the conformational changes in soluble Tau and maintained its native conformation (Fig. S10A, B and C). To support the data, we further studied the effect of CBMCs on soluble full-length Tau (Fig. S11A, B and C) for their aggregation. Tau aggregates were not observed, which indicated that the Co(II)-complexes did not lead to the formation of aggregates during initial stages of Tau assembly. 


\section{Destabilization of preformed Tau fibrils}

We further investigated the role of CBMCs on disassembly of Tau PHFs. This would enhance both properties of aggregation inhibition and disaggregation of Tau. The preformed Tau aggregates were incubated with various concentrations of L1, L2 and L3 and it was observed that L3 was more effective in disaggregating Tau when compared to L1 and L2 (Fig. 4A, B and C). At a concentration of $0.5 \mathrm{mg} \mathrm{mL}^{-1}$, L3 showed about $77.4 \%$ of inhibition, but L1 and L2 showed 73.5\% and 71.9\% inhibition, respectively (Fig. 4D). Furthermore, SDS-PAGE analysis showed a decrease in the aggregates by CBMCs in time dependent manner (Fig. 4E, F and G). Unlike the ThS fluorescence, SDS-PAGE did not show decrease in the intensity of higher order aggregates of Tau. However, at a concentration of $0.5 \mathrm{mg} \mathrm{mL}^{-1} \mathrm{~L} 3$ exhibited decrease in Tau aggregates and at 24 hours the decrease in aggregates by L3 was prominently observed. At 120 hours of incubation, CBMCs effectively disintegrated Tau aggregates as ascertained by the lower intensity of higher molecular weight Tau around $250 \mathrm{kDa}$ (indicated by red arrow). Initially, at 0 hour of incubation, no changes were observed in the morphology of aggregates in presence of CBMCs (Fig. S8B, C and D), when compared to untreated Tau aggregates (Fig. S8A). However, at the end of 120 hours, there was a definite decrease in the formation of PHFs (Fig. 6A, B, C and D). Overall, these results suggest the efficacy of CBMCs in preventing the formation of Tau aggregates that could be toxic and hence, it can be a potent therapeutic agent to AD.

In recent years, several drugs failed in the clinical trials which emphasize the urge to develop and screen different natural as well as synthetic molecules to target AD pathology. Although AD has multifaceted effectors like kinases, proteases, oxidative stress etc., the structure of the protein plays very important role in interaction and further change in its conformation can lead to either oligomers or aggregates formation. It has been suggested that the oligomeric precursors to amyloid fibrils may substantially be more toxic than the fibers themselves. Even if this was the case, amyloid fibrils are likely to play an important role, either as reservoirs or sinks to toxic oligomers. Hence, a detailed screening of compounds could help in discovering potential drugs that prevent protein aggregation in AD. The role of metal ions in association with proteins and leading to their aggregation is a well-known phenomenon. ${ }^{35}$ Metal ions such as copper(II), zinc(II), aluminium(III) and iron(III) are known to cause protein aggregation, but our results suggest that molecular cobalt(II) complexes have a paradoxical effect. Previously, Rajendran et al., have 
reported the deposition of metals such as iron, copper and zinc in the AD brain, which revealed increased metal accumulation in comparison with healthy brain tissue. ${ }^{36}$ Aluminium is known for the accumulation of Tau in cultured neurons and AD pathology. ${ }^{37}$ The animal studies revealed that injecting PHFs with and without aluminium salts led to distinct effects. The aluminium salts caused the deposition of Amyloid $\beta$ and several other proteins along with Tau. ${ }^{38}$ Moreover, the in vitro studies also showed that aluminium caused the formation of higher order aggregates, as examined by SDS-PAGE. Aluminium was known to cause aggregation in phosphorylated Tau. Aluminium also effects Tau aggregation by reducing the activity of PP2A, an enzyme essential for dephosphorylation of Tau and activating kinases such as $\operatorname{cdk} 5$ and GSK3 $\beta .^{39,40}$ Kawahara et al., showed that prolonged exposure to aluminium leads to conformational changes in Amyloid $\beta$ and its aggregation. ${ }^{41}$

In our present observations, the biochemical studies revealed the potency of CBMCs in preventing Tau polymerization. Copper interacts with both Tau and Amyloid $\beta$, driving the pathology of the AD. The oxidative property of copper that leads to Tau aggregation via. cysteine residues is well understood. ${ }^{23}$ Studies in $3 \mathrm{XTg}$-AD mice showed that treatment with copper led to activation of $\mathrm{cdk} 5 / \mathrm{p} 25$ which caused hyper phosphorylation of Tau. ${ }^{42}$ Voss et al., elucidated that copper led to hyper phosphorylation of Tau in SH-SY5Y cells, in Amyloid $\beta$ independent manner. ${ }^{43}$ Copper is also known for reactive oxygen species (ROS) production in presence of Amyloid $\beta$ which leads to cytotoxicity. ${ }^{44}{ }^{45}$ Copper interacts with Amyloid $\beta$ and leads to a reduction in the content of $\beta$-sheet conformation that would further form amorphous aggregates. ${ }^{46}$ In our current studies, CBMCs did not drive conformational changes in full-length Tau. The soluble Tau has also manifested the signature of typical random-coil conformation in presence of metal complexes, which indicates that CBMCs does not drive conformational changes in Tau. Tau usually accumulates to form filamentous aggregates, but aluminium leads to the formation of amorphous aggregates. $^{47}$

In complement to the CD spectroscopy of soluble Tau, TEM analysis also suggests the absence of toxic Tau species. The interaction and affinity of the prion protein for copper and silver is dependent on their conformation of the protein. ${ }^{48}$ The SEC analysis clearly indicated that the higher order species of Tau aggregates was prevented by CBMCs (Fig. S12). 


\section{Direct interaction of CBMCs with Tau}

Isothermal titration calorimetry (ITC) is the direct method to obtain free energy $(\Delta \mathrm{G})$, enthalpy $(\Delta \mathrm{H})$ and entropy $(\Delta \mathrm{S})$ changes along with dissociation constant $\left(\mathrm{K}_{\mathrm{D}}\right)$ and number of binding sites $(\mathrm{N})$ for ligand on the protein. Soragni et al., and Zhu et al., in individual studies employed ITC to analyse the binding of copper and lead, respectively. ${ }^{23,49}$ The ITC titration yielded differential power values during interaction of Tau with L2 (Fig. 5A). These values were integrated and exothermic peaks were obtained (Fig. 5B). The negative $\Delta \mathrm{G}$ value, -7.51 revealed the spontaneity of binding. The titration suggested binding of L2 to Tau with dissociation constant $\left(\mathrm{K}_{\mathrm{D}}\right)$ of $5.09 \mu \mathrm{M} \pm$ $5.84 \mu \mathrm{M}$, a weak interaction. The fitting by one set of sites resulted in the N value (number of sites on Tau) of 0.64 \pm 0.132 . The binding indicated small enthalpy changes $(\Delta \mathrm{H})$ with negative entropy of $-0.654 \pm 0.226$ and -6.86 $\mathrm{kcal} / \mathrm{mol}$, respectively.

\section{Cobalt inhibits the human Tau aggregation mediated cytotoxicity:}

Metals are an essential components of the brain at physiological levels but, their accumulation at higher concentration would be detrimental. Metals are known to exert toxicity in either of the following ways, by inhibiting PP2A or activating kinases such as $\operatorname{cdk} 5 / \mathrm{p} 25$, GSK3 $\beta$ etc. The neurons isolated from hippocampus were treated with iron, this led to oxidative stress which ultimately caused Tau hyperphosphorylation via., cdk5/p25 complex. ${ }^{50}$ Similarly, studies in the rat primary cortical neurons showed that zinc caused phosphorylation of Tau at Ser262, which was marked as an early pathological events in $\mathrm{AD} \cdot{ }^{51}$ Here, the toxicity of these compounds were analysed by treating the SH-SY5Y cells with CBMCs in presence of Tau aggregates (Fig. 6E). The neuronal SHSY5Y cells treated with Tau aggregates showed 59\% cell toxicity at the concentration of $5 \mu \mathrm{M}$. However, this toxicity was arrested in the presence of CBMCs treatment. Interestingly, CBMCs displayed a dose-dependent inhibition of the cytotoxic effect induced by full-length Tau aggregates (Fig. 6F). Further, at CBMCs concentration of $100 \mu \mathrm{g} / \mathrm{mL}$ the cell viability was almost restored to $80 \%$. These observations drive towards the conclusion that 
CBMCs are non-toxic to cells and moreover they reduce the toxicity of Tau aggregates, thus maintaining the cell viability.

Further, at CBMCs concentration of $100 \mu \mathrm{g} / \mathrm{mL}$ the cell viability was almost restored to $80 \%$. These observations drive towards the conclusion that CBMCs are non-toxic to cells and moreover they reduce the toxicity of Tau aggregates, thus maintaining the cell viability.

In summary, a newly developed molecular $\mathrm{Co}(\mathrm{II})$-complexes (CBMCs) showed significant role in inhibition and disaggregation of Tau. The cytotoxicity studies on human neuroblastoma SH-SY5Y cells revealed that the present CBMCs are non-toxic in nature under in vitro conditions. We firmly believe that the present molecular cobalt(II)complexes can be a potential therapeutic agent for Alzheimer's Disease and related neurodegenerative diseases.

\section{METHODS}

Materials or Chemicals: MES, heparin, BES, BSA, BCA and ThS were purchased from Sigma. IPTG and DTT were purchased from Calbiochem. Other chemicals such as ampicillin, $\mathrm{NaCl}$, EGTA etc. were purchased from MP. Cell culture related chemicals and plastics were purchased by Sigma and Thermo scientific Pvt Ltd.

Experiments were carried out using standard Schlenk techniques. All solvents were reagent grade or better. Deuterated solvents were used as received. Acetonitrile was refluxed over $\mathrm{P}_{2} \mathrm{O}_{5}$ and freshly distilled under argon atmosphere. Metal complexes $\left(\mathrm{CoCl}_{2}\right)$ and other chemicals used in the reactions were used without additional purification. Thin layer chromatography (TLC) was performed using silica gel pre-coated glass plates, which were visualized with UV light at $254 \mathrm{~nm}$ or under iodine. The column chromatography was performed with $\mathrm{SiO}_{2}(\mathrm{Silicycle}$ Siliaflash F60 (230-400 mesh). ${ }^{1} \mathrm{H}$ NMR (400 or $\left.500 \mathrm{MHz}\right),{ }^{13} \mathrm{C}\left\{{ }^{1} \mathrm{H}\right\}$ NMR (100 MHz) spectra were recorded on the NMR spectrometer. Deuterated chloroform was used as the solvent, and chemical shift values $(\delta)$ are reported in parts per million relative to the residual signals of this solvent $\left[\delta 7.26\right.$ for ${ }^{1} \mathrm{H}$ (chloroform-d), $\delta 77.2$ for ${ }^{13} \mathrm{C}\left\{{ }^{1} \mathrm{H}\right\}$ (chloroform-d). Abbreviations used in the NMR follow-up experiments: br, broad; s, singlet; d, doublet; t, triplet; q, quartet; m, multiplet. Mass spectra were obtained on a GCMS-QP 5000 instruments with ionization voltages of 70 eV. High-resolution mass spectra (HRMS) were obtained on a High-resolution mass spectra (HRMS) were obtained 
by fast atom bombardment (FAB) using a double focusing magnetic sector mass spectrometer and electron impact (EI) ionization technique (magnetic sector-electric sector double focusing mass analyzer).

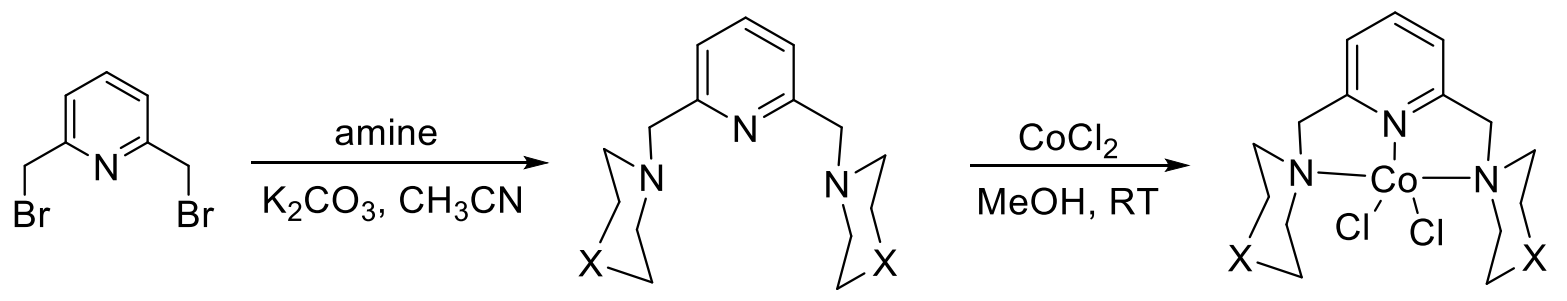

Scheme 1. Synthesis of cobalt complexes (L1-L3)

\section{Synthesis of Ligands:}

2,6-Bis(4-methylpiperazine-1-yl-methyl)pyridine (NNN-L1): A solution of 2,6-bis(bromomethyl)pyridine (0.8 g, $3.0 \mathrm{mmol})$ in acetonitrile $(45 \mathrm{~mL})$ was added drop wise to solution of 1-methylpiperazine $(0.669 \mathrm{~g}, 6.0 \mathrm{mmol})$ and $\mathrm{K}_{2} \mathrm{CO}_{3}(1.249 \mathrm{~g}, 9.0 \mathrm{mmol})$ in $\mathrm{CH}_{3} \mathrm{CN}(20 \mathrm{~mL})$, the resulting reaction mixture was allowed to stir for 14 hours at $80-85^{\circ} \mathrm{C}$, then cooled to room temperature, subsequently the reaction mixture was extracted with chloroform and water. The organic layer was collected, and evaporated in vacuum under the reduced pressure afforded yellow oil. Yield (0.82 g; 89\%). IR (KBr): v = 2945(s), 2520(m), 2042(m), 1452(s), 1029(s), 651(m). ${ }^{1} \mathrm{H}$ NMR (500MHz, CHLOROFORM-d) $\delta=7.59(\mathrm{~s}, 1 \mathrm{H}), 7.28(\mathrm{~s}, 2 \mathrm{H}), 3.66(\mathrm{~s}, 4 \mathrm{H}), 2.54(\mathrm{~s}, 8 \mathrm{H}), 2.46(\mathrm{~s}, 8 \mathrm{H}), 2.28(\mathrm{~s}, 6 \mathrm{H}) .{ }^{13} \mathrm{C} \mathrm{NMR}$ (126MHz, CHLOROFORM-d) $\delta=158.0,136.6,121.3,77.3,76.7,64.4,55.1,53.2,46.1$. HRMS (EI): $\mathrm{m} / z$ Calcd for $\mathrm{C}_{17} \mathrm{H}_{30} \mathrm{~N}_{5}: 304.2501$; Found: 304.2496 .

\section{2, 6-Bis(piperazin-1-yl-methyl)pyridine (NNN-L2):}

Step-1: synthesis of ${ }^{\text {boc }} \mathbf{N N N}$ : solution of 2, 6-bis(bromomethyl)pyridine $(1 \mathrm{~g}, 3.77 \mathrm{mmol})$ in acetonitrile $(40 \mathrm{~mL})$ was added drop wise to solution of 1-boc-peprazine $(1.4037 \mathrm{~g}, 7.54 \mathrm{mmol})$ and $\mathrm{K}_{2} \mathrm{CO}_{3}(1.56 \mathrm{~g}, 1.13 \mathrm{mmol})$ in $\mathrm{CH}_{3} \mathrm{CN}(20 \mathrm{~mL})$, the resulting reaction mixture was allowed to stir for 14 hours at $85^{\circ} \mathrm{C}$ after cooled to room temperature, the reaction mixture was extracted in chloroform. The organic fraction were combined and dried over anhydrous and evaporated in vacuum, afforded yellow oil. (Yield $0.8 \mathrm{~g} ; 80 \%)$. IR (KBr ): v = 3383(w), 2843(m), 
2077(m), 1639(s), 1431(m), 1273(m), 1014(m), 559(m) cm¹. HRMS (ESI): Calcd. For $\mathrm{C}_{25} \mathrm{H}_{41} \mathrm{~N}_{5} \mathrm{O}_{4}[\mathrm{M}+\mathrm{H}]^{+}$ 475.62; found 476.3244 .

Step-2: synthesis of NNN-L2: ${ }^{\text {boc }} \mathrm{NNN}(0.8 \mathrm{~g})$ was dissolved $\mathrm{MeOH}(15 \mathrm{~mL})$ and followed by added $1 \mathrm{~N} \mathrm{HCl}(8$ $\mathrm{mL}$ ), then the mixture was allowed to stir for $6 \mathrm{hrs}$ at $60^{\circ} \mathrm{C}$. After cooling the reaction mixture to room temperature, it was neutralized with aqueous solution of $5 \% \mathrm{NaHCO}_{3}$, then the solvent was evaporated in vacuum. The resulting sticky product was further dissolved in ethanol and filtered. The filtrate was concentrated in vacuum, afforded yellow oil product. Yield (0.75 g, 75\%). ${ }^{1} \mathrm{H}$ NMR $(300 \mathrm{MHz}, \mathrm{CDCl} 3) \delta$ 7.68-759(t. 1H), 7.45-7.29(d, 2H), 3.92-3.64(s, $4 \mathrm{H}), 3.15-2.72(\mathrm{~m}, 8 \mathrm{H}), 2.71-2.42(\mathrm{~s}, 8 \mathrm{H}), 2.43-2.21(\mathrm{~s}, 2 \mathrm{H})$.HRMS (ESI): calcd. For $\mathrm{C}_{15} \mathrm{H}_{25} \mathrm{~N}_{5}[\mathrm{M}+\mathrm{H}]^{+} 275.39$; found 276.21.

Synthesis of 2, 6-Bis(morpholinomethyl)pyridine(NNN-L3): A solution of 2, 6-bis(bromomethyl)pyridine (0.3 g, $1.13 \mathrm{mmol})$ in acetonitrile $(30 \mathrm{~mL})$ was added drop wise to solution of morpholine $(0.197 \mathrm{~g}, 2.26 \mathrm{mmol})$ and $\mathrm{K}_{2} \mathrm{CO}_{3}$ $(0.468 \mathrm{~g}, 3.39 \mathrm{mmol})$ in $\mathrm{CH}_{3} \mathrm{CN}(15 \mathrm{~mL})$, the resulting reaction mixture was allowed to stir for 14 hours at $80-85^{\circ} \mathrm{C}$, then cooled to room temperature, subsequently the reaction mixture was extracted with chloroform and water. The organic layer was collected, and evaporated in vacuum under the reduced pressure afforded colorless solid. Yield $(0.282 \mathrm{~g}, 90 \%) . \mathrm{IR}(\mathrm{KBr}): v=2800(\mathrm{~m}), 1575(\mathrm{~m}), 1454(\mathrm{~m}), 1298(\mathrm{~m}), 1111(\mathrm{~s}), 906(\mathrm{~m}) .{ }^{1} \mathrm{H}$ NMR $(500 \mathrm{MHz}$, CHLOROFORM-d) $\delta=7.65-7.52(\mathrm{~m}, 1 \mathrm{H}), 7.31(\mathrm{~d}, J=7.6 \mathrm{~Hz}, 2 \mathrm{H}), 3.84-3.69(\mathrm{~m}, 8 \mathrm{H}), 3.66(\mathrm{~s}, 4 \mathrm{H}), 2.51(\mathrm{~s}$, 8H). ${ }^{13} \mathrm{C}$ NMR (126MHz, CHLOROFORM-d) $\delta=157.7,136.7,121.4,77.3,76.7,66.9,64.8,53.7$.

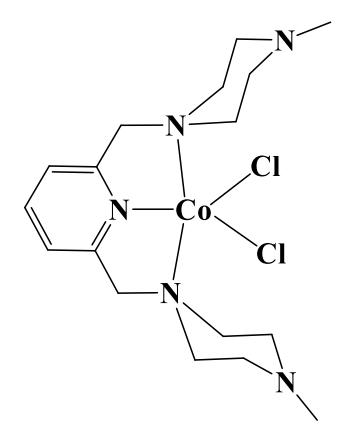

NNN-L1CoCl

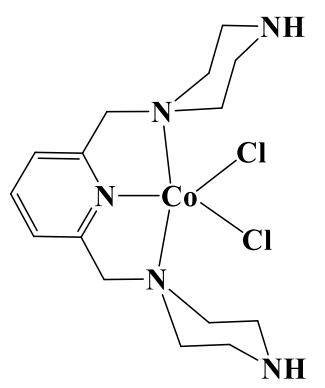

NNN-L2CoCl

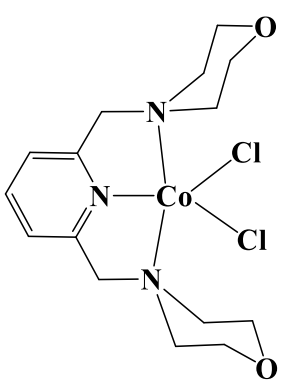

NNN-L3CoCl

Chart 1. NNN-pincer type cobalt complexes 
Synthesis of (NNN-L1)CoCl ${ }_{2}$ : Cobalt chloride hexahydrate $(0.312 \mathrm{~g}, 1.34 \mathrm{mmol})$ in methanol $(15 \mathrm{~mL})$ was added drop wise to solution of NNN-L1 $(0.408 \mathrm{~g}, 1.34 \mathrm{mmol})$ in $\mathrm{MeOH}(15 \mathrm{~mL})$ with stirring. The resulting reaction mixture was allowed to stir for 3 hours at room temperature. The resulting solution was evaporated under vacuum afforded the blue color solid; the solid was washed with diethyl ether and dried at air. Yield (0.54 g; 93\%). IR (KBr): $v=2924(\mathrm{~s}), 2314(\mathrm{~m}), 1612(\mathrm{~m}), 1462(\mathrm{~s}), 1207(\mathrm{~m}), 972(\mathrm{~m})$. HRMS (EI): $\mathrm{m} / \mathrm{z}$ Calcd for $\mathrm{C}_{17} \mathrm{H}_{30} \mathrm{~N}_{5} \mathrm{Cl}_{2} \mathrm{Co}: 433.1210$ Found: 433.1205 .

Synthesis of (NNN-L2)CoCl $\mathbf{L}_{2}$ : Cobalt chloride hexahydrate $(0.086 \mathrm{~g}, 0.36 \mathrm{mmol})$ was added to solution of NNN$\mathrm{L} 1(0.1 \mathrm{~g}, 0.36 \mathrm{mmol})$ in $\mathrm{MeOH}(10 \mathrm{~mL})$ with stirring. The resulting reaction mixture was allowed to stir for 3 hours at room temperature. The resulting solution was concentrated in a vacuum afforded the blue color solid; the solid was washed with diethyl ether and dried at air. Yield (0.132 g; 90\%). IR (KBr ): v = 3446(w), 1633(s), 1460(m), 1165(m), 989(m), 613(m). HRMS (ESI): calcd. For $\mathrm{C}_{16} \mathrm{H}_{28} \mathrm{Cl}_{2} \mathrm{CoN}_{5}[\mathrm{M}+\mathrm{Na}]^{+}$405.23; found 429.24.

Synthesis of (NNN-L3) $\mathbf{C o C l}_{2}$ : Cobalt chloride hexahydrate $(0.129 \mathrm{~g}, 0.54 \mathrm{mmol})$ in methanol $(8 \mathrm{~mL})$ was added drop wise to solution of NNN-L3 $(0.151 \mathrm{~g}, 0.54 \mathrm{mmol})$ in $\mathrm{MeOH}(10 \mathrm{~mL})$ with stirring. The resulting reaction mixture was allowed to stir for 3 hours at room temperature. The resulting solution was evaporated under vacuum afforded the blue colored solid and the solid was washed with diethyl ether and dried at air. Yield (0.21 g, 95\%). IR $(\mathrm{KBr}): v=2958(\mathrm{~s}), 2841(\mathrm{~m}), 1610(\mathrm{~s}), 1450(\mathrm{~m}), 1290(\mathrm{~m}), 1111(\mathrm{~s}), 999(\mathrm{~m}), 869(\mathrm{~s}), 815(\mathrm{~m})$. HRMS (EI): $\mathrm{m} / z$ Calcd for $\mathrm{C}_{17} \mathrm{H}_{28} \mathrm{~N}_{3} \mathrm{Cl}_{2} \mathrm{Co}$ : 403.0992 ; Found: 403.0987.

Expression and Purification of Tau: The recombinant full-length and four repeat Tau were expressed in BL21* strain of E.coli. Cells were induced with $0.5 \mathrm{mM}$ IPTG after the OD at $\mathrm{A}_{600}$ reached to 0.5 to 0.6 . The cells were allowed to grow at $37^{\circ} \mathrm{C}$ post-induction and were harvested by pelleting at $4000 \mathrm{rpm}$, at $4^{\circ} \mathrm{C}$ for 10 minutes. The pellet obtained was resuspended in $50 \mathrm{mM}$ MES buffer $\mathrm{pH} 6.8$ containing $1 \mathrm{mM}$ EGTA, $2 \mathrm{mM} \mathrm{MgCl} 2,5 \mathrm{mM}$ DTT, $1 \mathrm{mM}$ PMSF, protease inhibitor cocktail and was lysed by using constant cell disruption system. The purification was done as described previously with minor changes. ${ }^{52}$ The concentrated protein was aliquoted, snap freezed and stored in $-80^{\circ} \mathrm{C}$ until further used. The concentration was estimated using bichinchoninic acid (BCA) method.

Preparation of Tau aggregates: Tau was induced to aggregates formation as described previously with minor modifications. ${ }^{52}$ In presence of heparin $(17,500 \mathrm{Da})$ at the ratio of $4: 1$, Tau was polymerized in assembly buffer 
containing $20 \mathrm{mM}$ BES, pH 7.4, $25 \mathrm{mM} \mathrm{NaCl}, 1 \mathrm{mM}$ DTT, $0.01 \% \mathrm{NaN}_{3}$ and protease inhibitor cocktails. The reaction mixture was incubated at $37^{\circ} \mathrm{C}$ and the aggregates formation was monitored by $\mathrm{ThS}$ fluorescence, ${ }^{53,54}$ SDSPAGE and TEM at certain time intervals. Tau protein was allowed to assemble in presence and absence of compounds in increasing concentrations with constant Tau concentrations of $0.91 \mathrm{mg} \mathrm{mL}^{-1}$. The changes in the conformation of Tau protein was monitored by CD spectroscopy.

Disaggregation assay: The potency of the metal complexes for disaggregating the preformed Tau aggregates was analyzed. Soluble Tau was incubated at $37^{\circ} \mathrm{C}$ for PHF assembly. The formation of aggregates was analyzed by $\mathrm{ThS}$ fluorescence assay and SDS-PAGE. Thus, formed aggregates were diluted to $0.91 \mathrm{mg} \mathrm{mL}^{-1}$ final concentration of 20 mM BES buffer, pH 7.4 and further the mixture was incubated with increasing concentration of metal complex as discussed earlier.

Thioflavin S fluorescence assay: $5 \mu \mathrm{l}$ of reaction mixture was diluted with $8 \mu \mathrm{M}$ ThS in $50 \mathrm{mM}$ ammonium acetate, $\mathrm{pH} 7.0$ and added to 384 well plates in triplicates. Subsequently blank was also prepared for subtracting background fluorescence. The plate was incubated for 20 minutes in dark before measuring ThS fluorescence, at an emission wavelength of $521 \mathrm{~nm}$ by exciting it at $440 \mathrm{~nm}$ in Tecan Infinite 200 PRO multimode microplate reader.

SDS-PAGE analysis for Tau aggregates: The effect of the compounds on inhibiting the aggregates formation by Tau was observed by SDS-PAGE. ${ }^{55,56}$ The reaction mixture incubated with and without compound were collected at different time intervals of 0 hour, 24 hour and 72 hours (end point) and resolved 10\% SDS-PAGE using miniVE Vertical Electrophoresis System from GE healthcare. Further the SDS-PAGE were quantified and analyzed using Gel Doc ${ }^{\mathrm{TM}} \mathrm{XR}+$ System and image lab software.

Soluble Tau Assay: The soluble Tau was studied in presence of metal complexes alone to analyze the conformational changes occurring due to the compound. $0.91 \mathrm{mg} \mathrm{mL}^{-1}$ was incubated for 1 hour at $37^{\circ} \mathrm{C}$ with and without different concentrations of $0.01 \mathrm{mg} \mathrm{mL}^{-1}, 0.025 \mathrm{mg} \mathrm{mL}^{-1}, 0.05 \mathrm{mg} \mathrm{mL}^{-1}$ and $0.1 \mathrm{mg} \mathrm{mL}^{-1}$ of metal complexes. At the end of one hour the samples were analyzed by SDS-PAGE, TEM and CD spectroscopy to monitor the formation of aggregates and change in Tau conformation, respectively. 
CD spectroscopy: The conformational changes in Tau was analyzed by CD spectroscopy in the far UV region. Tau is a random coiled protein and upon aggregation it acquires $\beta$-sheet conformation. The impact of the compounds on preventing the formation of $\beta$-sheet structure was studied by CD spectroscopy. The spectra was collected as described previously, in Jasco J-815 spectrometer, by using cuvette with $1 \mathrm{~mm}$ path length. ${ }^{57}$ The measurements were performed in the range of $250 \mathrm{~nm}$ to $190 \mathrm{~nm}$, with a data pitch of $1.0 \mathrm{~nm}$, scanning speed of $100 \mathrm{~nm} / \mathrm{min}$. All the spectra were obtained at $25^{\circ} \mathrm{C}$. The reaction mixture was diluted to $0.13 \mathrm{mg} \mathrm{mL}^{-1}$ in $50 \mathrm{mM}$ phosphate buffer, $\mathrm{pH}$ 6.8. The effect of compound on soluble Tau was also studied by incubating Tau along with compounds alone at $37^{\circ} \mathrm{C}$ and the spectra was read at $25^{\circ} \mathrm{C}$.

Transmission Electron Microscopy (TEM): The extent of aggregates formed in presence of the metal complexes was analyzed by TEM (Tecnai T-20). The assay mixture was diluted to $0.04 \mathrm{mg} \mathrm{mL}^{-1}$ final concentration, spotted on the carbon coated copper grid of 400 mesh and incubated for 45 seconds. The excess Tau aggregates were removed by incubating the grid in water for 30 seconds and this was repeated twice. The grid was further stained by $2 \%$ uranyl acetate for 1 minute to observe the morphology of aggregates under TEM.

Size-exclusion chromatography (SEC): The HMW species formed by Tau polymerization was analyzed by SEC ${ }^{58-60}$ Tau protein was diluted to a concentration of $4.58 \mathrm{mg} \mathrm{mL}^{-1}$ in assembly buffer along with heparin in a ratio of $4: 1$ and incubated at $37^{\circ} \mathrm{C}$ in presence and absence of $0.1 \mathrm{mg} \mathrm{mL} \mathrm{L}^{-1}$ of NNN-L2CoCl 2 . Tau was subjected to SEC using superdex 75 PG in order to resolve aggregated Tau from the soluble, which was accessed as decrease in retention volume at different time points of 0,2 and 24 hours in presence and absence of NNN-L2CoCl${ }_{2}$.

Isothermal titration calorimetry: Isothermal titration calorimetry (ITC) was carried out to understand the thermodynamics behind Tau interaction with CBMCs. Here, the titration was done using $2.3 \mathrm{mg} / \mathrm{mL}$ of full-length Tau and $0.407 \mathrm{mg} / \mathrm{mL}$ of $\mathrm{L} 2$. The titrations were recorded in MicroCal PEAQ-ITC at $25^{\circ} \mathrm{C}$. The titration was conducted by giving 19 injections, first injection of $0.4 \mu \mathrm{L}$ was followed by injections of $2 \mu \mathrm{L}$ each with 180 seconds spacing at stirring speed of $650 \mathrm{rpm}$. Tau and L2 were prepared in $20 \mathrm{mM}$ BES containing $50 \mathrm{mM} \mathrm{NaCl}$ at $\mathrm{pH}$ 7.4. The samples were re-buffered, filtered and loaded. The sample cell was loaded with $200 \mu \mathrm{L}$ of full-length Tau and syringe 
with $40 \mu \mathrm{L}$ of L2. The data was analyzed in MicroCal PEAQ-ITC analysis software and fitted to one set of site model.

Cytotoxicity assay: SH-SY5Y cells were cultured in Dulbecco's Modified Eagle Medium (DMEM)-F12 media (Gibco) supplemented with 20\% FBS, $100 \mathrm{U} / \mathrm{ml}$ penicillin and $100 \mathrm{U} / \mathrm{ml}$ streptomycin. For the cell toxicity studies, sub-confluent cells were harvested by trypsinization and 25,000 cells/well were seeded in 96 well plate (100 $\mu 1 /$ well). The cells were then incubated overnight at $37^{\circ} \mathrm{C}$. Post incubation, the cells were treated with $100 \mu$ of DMEM containing $5 \mu \mathrm{M}$ full-length Tau aggregates, followed by the indicated amounts of the CBMCs. The fulllength Tau aggregates alone was used as control. After 12 hours of incubation at $37^{\circ} \mathrm{C}$, cell viability was evaluated using thiazolyl-blue-tetrazolium-bromide (MTT) assay. Each treatment was performed in triplicates. Briefly, $10 \mu 1$ of $5 \mathrm{mg} \mathrm{mL}^{-1}$ MTT was added into each well and further incubated for 4 hours at $37^{\circ} \mathrm{C}$. Later, $100 \mu 1$ of DMSO was added into each well and the colour intensity was measured using ELISA Reader at $570 \mathrm{~nm}$. The percentage of cell viability was calculated as following. Cells viability $(\%)=$ O.D. $(570 \mathrm{~nm})$ in the presence of full-length Tau with or without inhibitor*100.

\section{ASSOCIATED CONTENT}

Supporting Information

Detailed Materials and Methods; Supplemental Figures regarding aggregation assay, soluble Tau and Sizeexclusion data analysis, and electron microscopy data. This material is available free of charge via the Internet at http://pubs.acs.org.

\section{AUTHOR INFORMATION}

\section{Corresponding Author}

To whom correspondence should be addressed:

\section{Dr. Subashchandrabose Chinnathambi,}

Email: s.chinnathambi@ncl.res.in

For synthetic chemistry part,

Dr. Ekambaram Balaraman, 
Email: eb.raman@ncl.res.in

\section{Notes}

The authors declare no competing financial interest.

\section{Abbreviations used}

AD, Alzheimer's Disease; A $\beta$, Amyloid $\beta$; CBMCs, Cobalt-Based Metal Complexes; NFTs, Neurofibrillary Tangles; MTs, Microtubules; PHFs, Paired Helical Filaments; APP, Amyloid Precursor Protein

\section{Acknowledgements}

This research was supported by the DST-SERB (SB/YS/LS-355/2013) and CSIR-NCL (MLP029526). EB acknowledges funding from SERB (SB/FT/CS-065/2013). Tau constructs were kindly gifted by Prof. Roland Brandt from University of Osnabruck, Germany and Prof. Jeff Kuret from Ohio State University College of Medicine, USA. NVG acknowledges to UGC and SPM, and VGL thanks to CSIR for fellowships.

\section{References:}

1 Kosik, K. S., Joachim, C. L., and Selkoe, D. J. (1986) Microtubule-associated protein tau (tau) is a major antigenic component of paired helical filaments in Alzheimer disease. Proc Natl Acad Sci U S A. $83(11): 4044-8$.

2 Kosik, K. S., and McConlogue, L. (1994) Microtubule-Associated Protein Function:Lessons From Expression in Spodoptera frugiperda Cells. Cell Motility and the Cytoskeleton 28:195-198.

3 Ebneth, A., Drewes, G., Mandelkow, E. M., and Mandelkow, E. (1999) Phosphorylation of MAP2c and MAP4 by MARK kinases leads to the destabilization of microtubules in cells. Cell Motil Cytoskeleton 44(3):209-24. 
4 Ebneth, A., Godemann, R., Stamer, K., Illenberger, S., Trinczek, B., and Mandelkow, E. (1998) Overexpression of tau protein inhibits kinesin-dependent trafficking of vesicles, mitochondria, and endoplasmic reticulum: implications for Alzheimer's disease. J Cell Biol. 2;143(3):777-94.

5 Wischik, C. M., Edwards, P. C., Lai, R. Y., Roth, M., and Harrington, C. R. (1996) Selective inhibition of Alzheimer disease-like tau aggregation by phenothiazines. Proc Natl Acad Sci U S A. $1 ; 93(20): 11213-8$. Alzheimer's disease. Biochem Pharmacol. 15;88(4):529-39.

7 Bulic, B., Pickhardt, M., Schmidt, B., Mandelkow, E. M., Waldmann, H., and Mandelkow, E. (2009) Development of tau aggregation inhibitors for Alzheimer's disease. Angew Chem Int Ed Engl. 48(10):1740-52.

8 Akoury, E., Pickhardt, M., Gajda, M.; Biernat, J., Mandelkow, E., and Zweckstetter, M. (2013) Mechanistic basis of phenothiazine-driven inhibition of Tau aggregation. Angew Chem Int Ed Engl. $18 ; 52(12): 3511-5$

9. Bulic, B., Pickhardt, M., Mandelkow, E. M., and Mandelkow, E. (2010) Tau protein and tau aggregation inhibitors. Neuropharmacology, 59(4-5):276-89.

10 Paranjape, S. R., Riley, A. P., Somoza, A. D., Oakley, C. E., Wang, C. C., Prisinzano, T. E., Oakley, B. R., and Gamblin, T. C. (2015) Azaphilones inhibit tau aggregation and dissolve tau aggregates in vitro. ACS Chem Neurosci. 20;6(5):751-60.

11 Paranjape, S. R., Chiang, Y. M., Sanchez, J. F., Entwistle, R., Wang, C. C., Oakley, B. R., and Gamblin, T. C. (2014) Inhibition of Tau aggregation by three Aspergillus nidulans secondary metabolites: 2, $\omega$-dihydroxyemodin, asperthecin, and asperbenzaldehyde. Planta Med. 80(1):77-85. 
12 Calcul, L., Zhang, B., Jinwal, U. K., Dickey, C. A., and Baker, B. J. (2012) Natural products as a rich source of tau-targeting drugs for Alzheimer's disease. Future Med Chem. 4(13):1751-61.

13 Fang, L., Gou, S., Fang, X., Cheng, L., and Fleck, C. (2013) Current progresses of novel natural products and their derivatives/ analogs as anti-Alzheimer candidates: an update. Mini Rev Med Chem. 1;13(6):870-87.

14 Cisek, K., Cooper, G. L., Huseby, C. J., and Kuret, J. (2014) Structure and mechanism of action of tau aggregation inhibitors. Curr Alzheimer Res. 11(10):918-27.

15 Li, W., Sperry, J. B., Crowe, A., Trojanowski, J. Q., Smith, A. B. L, and Lee, V. M. (2009) Inhibition of tau fibrillization by oleocanthal via reaction with the amino groups of tau. $\mathrm{J}$ Neurochem. 110(4):1339-51.

16 Miura, T., Suzuki, K., Kohata, N., and Takeuchi, H. (2000) Metal binding modes of Alzheimer's amyloid beta-peptide in insoluble aggregates and soluble complexes. Biochemistry. 13;39(23):702431.

17 Ritchie, C. W., Bush, A. I., Mackinnon, A., Macfarlane, S., Mastwyk, M., MacGregor, L., Kiers, L., Cherny, R., Li, Q. X., Tammer, A., Carrington, D., Mavros, C., Volitakis, I., Xilinas, M., Ames, D., Davis, S., Beyreuther, K., Tanzi, R. E., and Masters, C. L. (2003) Metal-protein attenuation with iodochlorhydroxyquin (clioquinol) targeting Abeta amyloid deposition and toxicity in Alzheimer disease: a pilot phase 2 clinical trial. Arch Neurol. 60(12):1685-91.

18 Savelieff, M. G., Lee, S., Liu, Y., and Lim, M. H. (2013) Untangling amyloid- $\beta$, tau, and metals in Alzheimer's disease. ACS Chem Biol. 17;8(5):856-65.

19 Tõugu, V., Karafin, A., Zovo, K., Chung, R. S., Howells, C., West, A. K., and Palumaa, P. (2009) $\mathrm{Zn}(\mathrm{II})$ - and $\mathrm{Cu}(\mathrm{II})$-induced non-fibrillar aggregates of amyloid-beta (1-42) peptide are transformed to amyloid fibrils, both spontaneously and under the influence of metal chelators. J Neurochem. 110(6):1784-95. 
20 Tõugu, V., Tiiman, A., and Palumaa, P. (2011) Interactions of $\mathrm{Zn}(\mathrm{II})$ and $\mathrm{Cu}(\mathrm{II})$ ions with Alzheimer's amyloid-beta peptide. Metal ion binding, contribution to fibrillization and toxicity. Metallomics. 3(3):250-61.

21 Miura, T., Suzuki, K., Kohata, N., and Takeuchi, H. (2000) Metal binding modes of Alzheimer's amyloid beta-peptide in insoluble aggregates and soluble complexes. Biochemistry. 13;39(23):7024-31.

22 Bousejra-ElGarah, F., Bijani, C., Coppel, Y., Faller, P., and Hureau, C. (2011) Iron(II) binding to amyloid- $\beta$, the Alzheimer's peptide. Inorg Chem. 19;50(18):9024-30.

23 Soragni, A., Zambelli, B., Mukrasch, M. D., Biernat, J., Jeganathan, S., Griesinger, C., Ciurli, S., Mandelkow, E., and Zweckstetter, M. (2008) Structural characterization of binding of Cu(II) to tau protein. Biochemistry. 14;47(41):10841-51.

24 Murayama, H., Shin, R. W., Higuchi, J., Shibuya, S., Muramoto, T., and Kitamoto, T. (1999) Interaction of aluminum with PHFtau in Alzheimer's disease neurofibrillary degeneration evidenced by desferrioxamine-assisted chelating autoclave method. Am J Pathol. 155(3):877-85.

25 Savory, J., Huang, Y., Herman, M. M., Reyes, M. R., and Wills, M. R. (1995) Tau immunoreactivity associated with aluminum maltolate-induced neurofibrillary degeneration in rabbits. Brain Res. $16 ; 669(2): 325-9$.

26 Craddock, T. J., Tuszynski, J. A., Chopra, D., Casey, N., Goldstein, L. E., Hameroff, S. R., and Tanzi, R. E. (2012) The zinc dyshomeostasis hypothesis of Alzheimer's disease. PLoS One. 7(3):e33552.

27 Yamamoto, A., Shin, R. W., Hasegawa, K., Naiki, H., Sato, H., Yoshimasu, F., and Kitamoto, T. (2002) Iron (III) induces aggregation of hyperphosphorylated tau and its reduction to iron (II) reverses the aggregation: implications in the formation of neurofibrillary tangles of Alzheimer's disease. J Neurochem. 82(5):1137-47. 
28 Lovell, M. A., Xiong, S., Xie, C., Davies, P., and Markesbery, W. R. (2004) Induction of hyperphosphorylated tau in primary rat cortical neuron cultures mediated by oxidative stress and glycogen synthase kinase-3. J Alzheimers Dis. 6(6):659-71.

29 Zheng, H., Youdim, M. B., and Fridkin, M. (2010) Site-activated chelators targeting acetylcholinesterase and monoamine oxidase for Alzheimer's therapy. ACS Chem Biol. 18;5(6):60310.

30 Stöckel, J., Safar, J., Wallace, A. C., Cohen, F. E., and Prusiner, S. B. (1998) Prion protein selectively binds copper(II) ions. Biochemistry. 19;37(20):7185-93.

31 Miura, T., Hori-i, A., Mototani, H., and Takeuchi, H. (1999) Raman spectroscopic study on the copper(II) binding mode of prion octapeptide and its $\mathrm{pH}$ dependence. Biochemistry. 31;38(35):11560-9.

32 Wang, W. and Mandelkow, E. (2016) Tau in physiology and pathology. Nat Rev Neurosci. 17(1):521. DOI: $10.1038 / \mathrm{nrn} .2015 .1$

33 Jeganathan, S., von Bergen, M., Brutlach, H., Steinhoff, H. J., and Mandelkow, E. (2006) Global hairpin folding of tau in solution. Biochemistry. 21;45(7):2283-93.

34 von Bergen, M., Friedhoff, P., Biernat, J., Heberle, J., Mandelkow, E. M., and Mandelkow, E. (2000) Assembly of tau protein into Alzheimer paired helical filaments depends on a local sequence motif ((306)VQIVYK(311)) forming beta structure. Proc Natl Acad Sci U S A. 9;97(10):5129-34.

35 Liu, Z., Song, F., Ma, Z. L., Xiong, Q., Wang, J., Guo, D., and Sun, G. (2016) Bivalent Copper Ions Promote Fibrillar Aggregation of KCTD1 and Induce Cytotoxicity. Sci Rep. 6;6:32658.

36 Rajendran, R., Minqin, R., Ynsa, M. D., Casadesus, G., Smith, M. A., Perry, G., Halliwell, B., and Watt, F. (2009) A novel approach to the identification and quantitative elemental analysis of amyloid 
deposits--insights into the pathology of Alzheimer's disease. Biochem Biophys Res Commun. 24;382(1):91-5.

37 Kawahara, M., Muramoto, K., Kobayashi, K., Mori, H., and Kuroda, Y. (1994) Aluminum promotes the aggregation of Alzheimer's amyloid beta-protein in vitro. Biochem Biophys Res Commun. 28;198(2):531-5.

38 Shin, R. W., Lee, V. M., and Trojanowski, J. Q. (1994) Aluminum modifies the properties of Alzheimer's disease PHF tau proteins in vivo and in vitro. J Neurosci. 14(11 Pt 2):7221-33.

39 Walton, J. R. (2007) An aluminum-based rat model for Alzheimer's disease exhibits oxidative damage, inhibition of PP2A activity, hyperphosphorylated tau, and granulovacuolar degeneration. J Inorg Biochem. 101(9):1275-84.

40 Prema, A., Justin Thenmozhi, A., Manivasagam, T., Mohamed Essa, M., and Guillemin, G. J. (2007) Fenugreek Seed Powder Attenuated Aluminum Chloride-Induced Tau Pathology, Oxidative Stress, and Inflammation in a Rat Model of Alzheimer's Disease. J Alzheimers Dis. 60(s1):S209-S220.

41 Kawahara, M., Kato, M., and Kuroda, Y. (2001) Effects of aluminum on the neurotoxicity of primary cultured neurons and on the aggregation of beta-amyloid protein. Brain Res Bull. 15;55(2):211-7.

42 Kitazawa, M., Cheng, D., and Laferla, F. M. (2009) Chronic copper exposure exacerbates both amyloid and tau pathology and selectively dysregulates cdk5 in a mouse model of AD. J Neurochem. 108(6):1550-60. DOI: 10.1111/j.1471-4159.2009.05901.

43 Voss, K., Harris, C., Ralle, M., Duffy, M., Murchison, C., and Quinn, J. F. (2014) Modulation of tau phosphorylation by environmental copper. Transl Neurodegener. 17;3(1):24.

44 Bondy, S. C., Guo-Ross, S. X., and Truong, A. T. (1998) Promotion of transition metal-induced reactive oxygen species formation by beta-amyloid. Brain Res. 13;799(1):91-6. 
45 Huang, X., Atwood, C. S., Hartshorn, M. A., Multhaup, G., Goldstein, L. E., Scarpa, R. C., Cuajungco, M. P., Gray, D. N., Lim, J., Moir, R. D., Tanzi, R. E., and Bush, A. I. (1999) The A beta peptide of Alzheimer's disease directly produces hydrogen peroxide through metal ion reduction. Biochemistry. 15;38(24):7609-16.

46 Huy, P. D., Vuong, Q. V., La Penna, G., Faller, P., and Li, M. S. (2016) Impact of Cu(II) Binding on Structures and Dynamics of A 342 Monomer and Dimer: Molecular Dynamics Study. ACS Chem Neurosci. 19;7(10):1348-1363.

47 Mizoroki, T., Meshitsuka, S., Maeda, S., Murayama, M., Sahara, N., and Takashima, A. (2007) Aluminum induces tau aggregation in vitro but not in vivo. J Alzheimers Dis. 11(4):419-27.

48 Valensin, D., Padula, E. M., Hecel, A., Luczkowski, M., and Kozlowski, H. (2016) Specific binding modes of $\mathrm{Cu}(\mathrm{I})$ and $\mathrm{Ag}(\mathrm{I})$ with neurotoxic domain of the human prion protein. $\mathrm{J}$ Inorg Biochem. 155:26-35.

49 Zhu, H-L., Meng, S-R., Fan, J-B., Chen, J., and Liang, Y. (2011) Fibrillization of Human Tau Is Accelerated by Exposure to Lead via Interaction with His-330 and His362. PLoS ONE. 6(9): e25020.

50 Egana, J. T., Zambrano, C., Nunez, M. T., Gonzalez-Billault, C., and Maccioni, R. B. (2003) Ironinduced oxidative stress modify tau phosphorylation patterns in hippocampal cell cultures. Biometals. 16(1):215-23.

51 Kwon, K. J., Lee, E. J., Cho, K. S., Cho, D. H., Shin, C. Y., and Han, S. H. (2015) Ginkgo biloba extract (Egb761) attenuates zinc-induced tau phosphorylation at Ser262 by regulating GSK3 $\beta$ activity in rat primary cortical neurons. Food Funct. 6(6):2058-67.

52 Barghorn, S., Biernat, J., and Mandelkow, E. (2005) Purification of recombinant tau protein and preparation of Alzheimer-paired helical filaments in vitro. Methods Mol Biol. 299:35-51.

53 Friedhoff, P., Schneider, A., Mandelkow, E. M., and Mandelkow, E. (1998) Rapid assembly of Alzheimer- 
like paired helical filaments from microtubule-associated protein tau monitored by fluorescence in solution. Biochemistry. 14;37(28):10223-30.

54 Santa-María, I., Pérez, M., Hernández, F., Avila, J., and Moreno, F. J. (2006) Characteristics of the binding of thioflavin S to tau paired helical filaments. J Alzheimers Dis. 9(3):279-85.

55 Taniguchi, S., Suzuki, N., Masuda, M., Hisanaga, S., Iwatsubo, T., Goedert, M., and Hasegawa, M. (2005) Inhibition of heparin-induced tau filament formation by phenothiazines, polyphenols, and porphyrins. J Biol Chem. 4;280(9):7614-23.

56 Masuda, M., Suzuki, N., Taniguchi, S., Oikawa, T., Nonaka, T., Iwatsubo, T., Hisanaga, S., Goedert, M., and Hasegawa, M. (2006) Small molecule inhibitors of alpha-synuclein filament assembly. Biochemistry. 16;45(19):6085-94.

57 Gorantla, N. V., Shkumatov, A. V., and Chinnathambi, S. (2017) Conformational Dynamics of Intracellular Tau Protein Revealed by CD and SAXS. Methods Mol Biol. 1523:3-20.

58 Flach, K., Hilbrich, I., Schiffmann, A., Gärtner, U., Krüger, M., Leonhardt, M., Waschipky, H., Wick, L., Arendt, T., and Holzer, M. (2012) Tau oligomers impair artificial membrane integrity and cellular viability. J Biol Chem. 21;287(52):43223-33.

Mirbaha, H., Holmes, B. B., Sanders, D. W., Bieschke, J., and Diamond, M. I. (2015) Tau Trimers Are the Minimal Propagation Unit Spontaneously Internalized to Seed Intracellular Aggregation. J Biol Chem. 12;290(24):14893-903.

60 Lasagna-Reeves, C. A., Castillo-Carranza, D. L., Sengupta, U., Guerrero-Munoz, M. J., Kiritoshi, T., Neugebauer, V., Jackson, G. R., and Kayed, R. (2012)Alzheimer brain-derived tau oligomers propagate pathology from endogenous tau. Sci Rep. 2:700. 


\section{Figure Legends}

Figure 1. (a) Domain organization of full-length Tau. The longest isoform of Tau is composed of 441 amino acids, with four repeats towards C-terminal that is crucial in both physiological processes as well as in AD pathology. In physiological conditions, it interacts with the tubulin dimer and helps in the assembly of MTs, while in the pathological condition they act as main nucleating centers and form the core of aggregates. The four repeats, $\mathrm{R} 1$ to $\mathrm{R} 4$ comprises of hexapeptides at the beginning of R2 and R3 which are the signature motifs responsible for Tau aggregation. (b) Chemical structure of cobalt-based metal complexes. (c) X-ray crystal-structure analysis of NNN-L2 $\mathrm{CoCl}_{2}$ with $50 \%$ probability of thermal ellipsoids. Selected bond length $\left[\mathrm{A}^{\circ}\right]$ and angle $\left[{ }^{\circ}\right]$ : $\mathrm{Co}(1)-\mathrm{N}(1)$ 2.0265, $\mathrm{Co}(1)-\mathrm{N}(2)$ 2.3215, $\mathrm{Co}(1)-\mathrm{N}(3)$ 2.4530, N(1)-Co(1)-N(2) 76.97, N(1)-Co(1)-N(3) 73.51, Cl(1)-Co(1)-Cl(2) 113.56

Figure 2. Cobalt-based complexes inhibits Tau aggregation. (a, b, c) The aggregation inhibition of full-length Tau in presence of CBMCs monitored by ThS fluorescence. The aggregation was induced from full-length Tau in presence of heparin as inducer and assembly buffer. The typical full-length Tau reaches its highest propensity of aggregation, but the incorporation of cobalt complex completely decrease its aggregation with increasing concentration of metal complex. (d) Although all three complexes are compelling in inhibiting aggregation process, the lower concentration of L2 is more effective in comparison with L1 and L3. At higher concentrations of 0.05 and 
$0.1 \mathrm{mg} \mathrm{mL}^{-1} \mathrm{~L} 2$ and L3 show maximum inhibition of about $97 \%$. L1 at its highest concentration of $0.1 \mathrm{mg} \mathrm{mL}^{-1}$ also has an inhibition of $97 \%$, which clearly suggests the proficiency of these metal complexes in inhibiting Tau aggregation. (e) Tau was analysed by SDS-PAGE at 0 hour, where the higher order species were observed in the highest concentration of CBMCs. (f) The higher order species were reduced at 24 hours. (g) When Tau was further analyzed at 72 hours these higher order species completely faded away. (h) The quantitative analysis of Tau in presence of CBMCs indicate the reduction in the formation of higher order aggregates with prolonged incubation (up to 72 hours), which reveals the potency of the complexes in preventing their aggregates formation.

Figure 3. Conformation of full-length Tau measured by CD spectroscopy. (a, b, c) The full-length Tau in native state unveils its random coil conformation, but upon aggregation it attains $\beta$-sheet conformation, represented in red. On addition of CBMCs in increasing concentrations of 0.01 and $0.1 \mathrm{mg} \mathrm{mL}^{-1} \mathrm{Tau}$ exhibits random coil conformation, indicating that CBMCs are effective in preventing $\beta$-sheet formation by Tau and thus, preventing its aggregation. (d) The morphology of Tau upon incubation with inducer alone and the typical morphology of Tau fibrils were observed. (e, f, g) The presence of CBMCs stipulated their ability to prevent aggregate formation. The inserts in each micrograph represent the morphology of Tau aggregates at a magnification of $0.5 \mu \mathrm{m}$.

Figure 4. Disaggregation of full-length Tau. $(a, b, c)$ The effect of disaggregation by L1, L2 and L3 conjugated to $\mathrm{CoCl}_{2}$ was analysed by ThS fluorescence assay. Tau aggregates were incubated with CBMCs in an increasing concentration of $0.01 \mathrm{mg} \mathrm{mL}^{-1}$ to $0.5 \mathrm{mg} \mathrm{mL}^{-1}$. (d) It was observed that the highest concentration of L1 showed $73.5 \%$ disaggregation, whereas L2 and L3 showed 71.9 and 77.4\% disaggregation respectively. (e, f, g) The presence of higher order aggregates were monitored by SDS-PAGE at different time points of incubation, at 0 hour (e) 24 hours (f) and 120 hours (g) where L3 was more efficient amongst the three in disintegrating Tau aggregates.

Figure 5. Interaction of Tau with CBMCs by ITC. (a) The differential power in terms of $\mu \mathrm{cal} / \mathrm{sec}$ was plotted for each injections of L2. (b) The raw data was integrated as kcal/mole of injection versus molar ration of ligand, L2. The fitting of integrated points using one set of sites revealed the interaction of L2 with Tau with $\mathrm{K}_{\mathrm{D}}$ of $5.09 \pm 5.84$ $\mu \mathrm{M}$. The $\mathrm{N}$ value of $0.643 \pm 0.132$ suggests binding of one $\mathrm{L} 2$ to two Tau molecules. 
Figure 6. Disaggregation of Tau PHFs by CBMCs. (a) Aggregates of full-length Tau was observed by TEM after 120 hours of incubation in absence of metal complexes. (b, c, d) Upon prolonged incubation with L1, L2 and L3 the aggregates were destructed into shorter filaments. The inserts in each micrograph represent the morphology of disaggregation of Tau at magnification of $0.5 \mu \mathrm{m}$. (e) Cytotoxicity assay. The MTT assay signified that there was no toxicity of CBMCs on SH-SY5Y cells. (f) The CBMCs showed protective effect and helped in overcoming the toxicity of Tau aggregates at higher concentrations. 


\section{Table of contents:}

Tau attains pathological conformation during Alzheimer's disease, which ultimately leads to neurodegeneration. The synthetic rationally designed molecular cobalt complexes (CBMCs) prevents the polymerization of Tau protein, as well as destabilizes the pre-formed fibrils. Thus, CBMCs are identified as a hit compound with significance to prevent $\mathrm{AD}$ as evidenced by various biochemical and biophysical analysis.

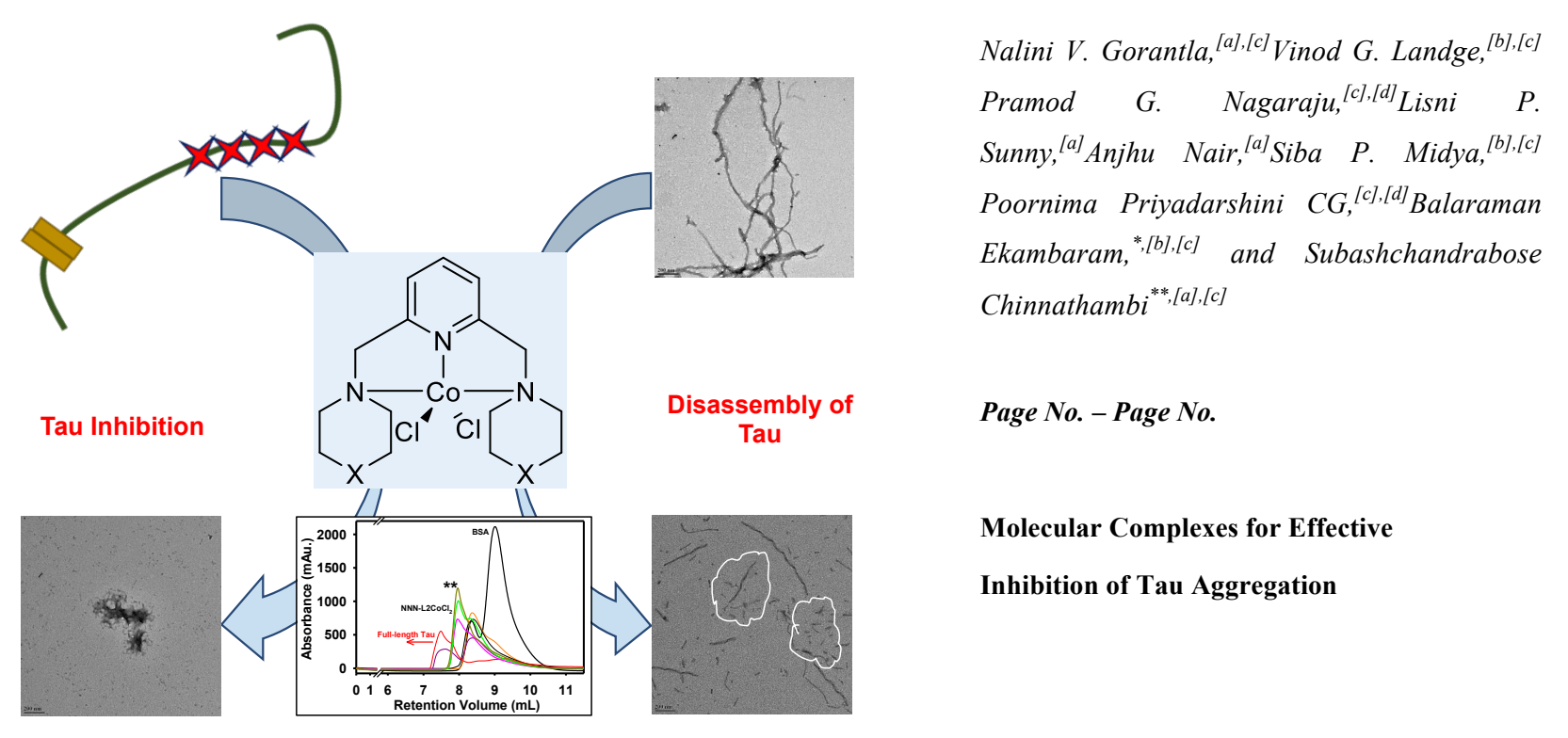




\section{Figure1}

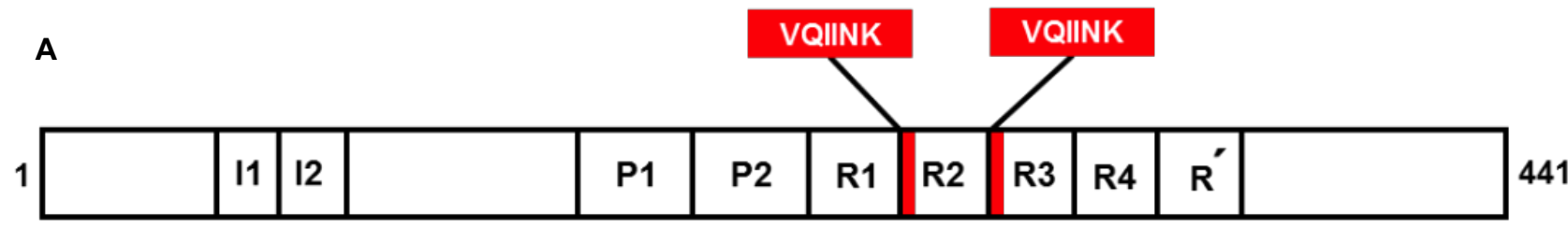<smiles></smiles>

NNN-L1CoCl 2<smiles>ClC1(Cl)CN2CCOCCN1Cc1cccc(n1)C21CCOCC1</smiles>

$\mathrm{NNN}-\mathrm{L}_{2} \mathrm{CoCl}_{2}$<smiles></smiles>

$\mathrm{NNN}-\mathrm{L} 3 \mathrm{CoCl}_{2}$

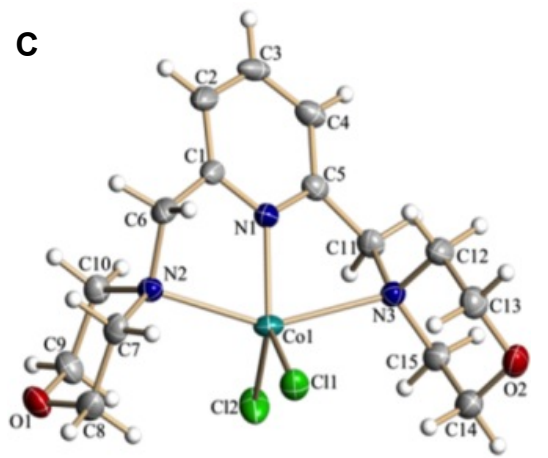




\section{Figure 2}

A

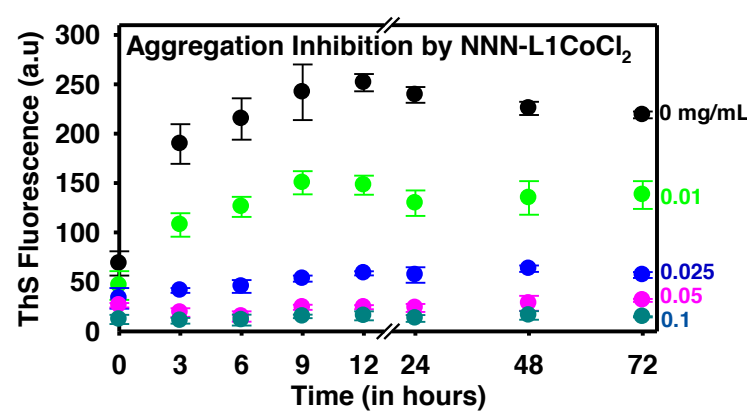

C

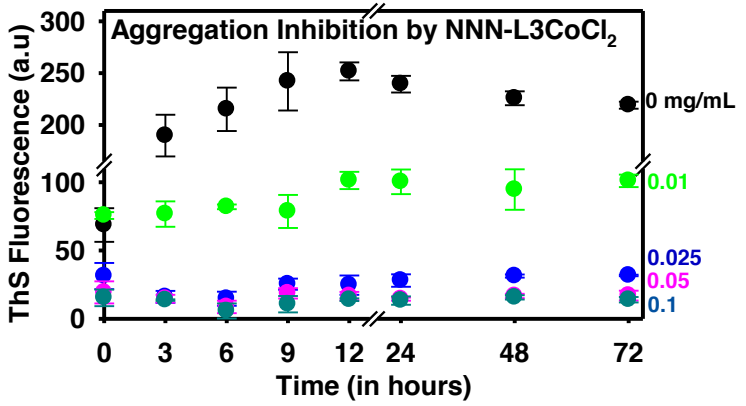

E

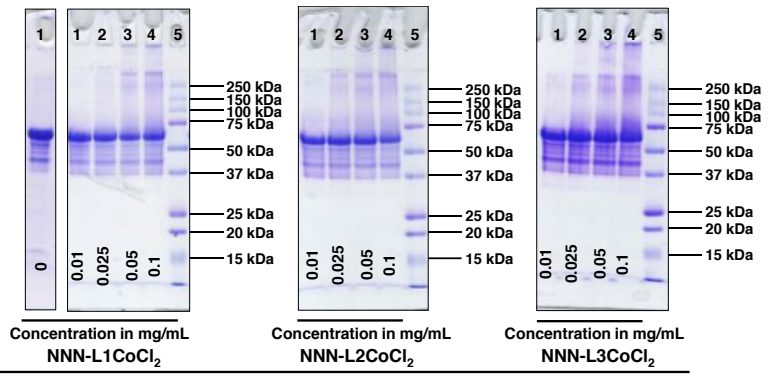

$\mathbf{F}$

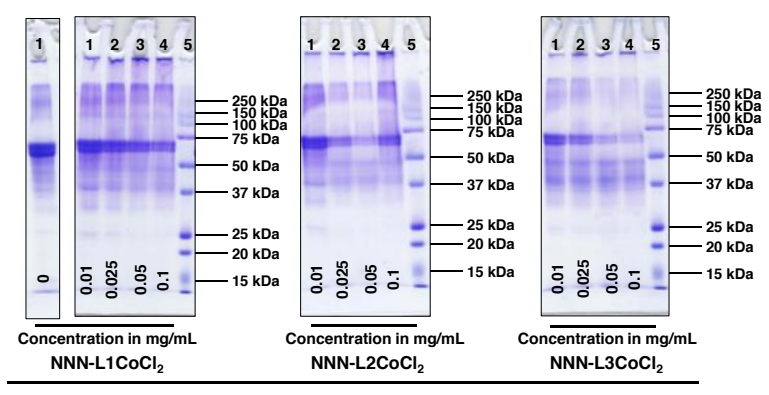

G

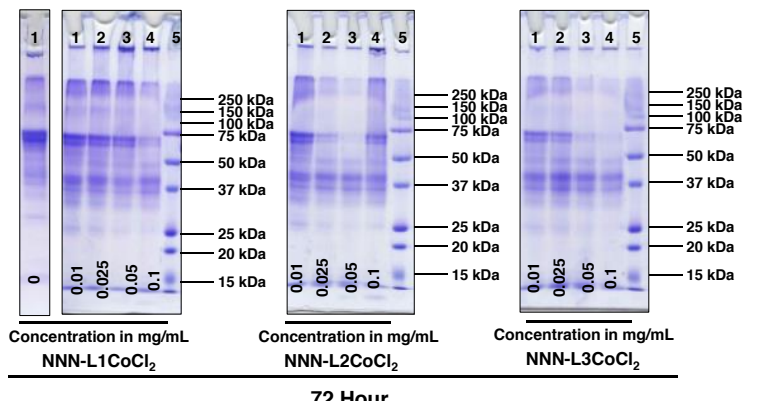

B

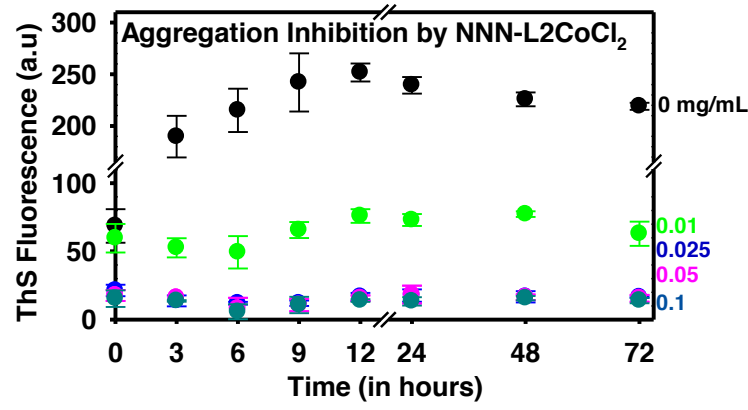

D

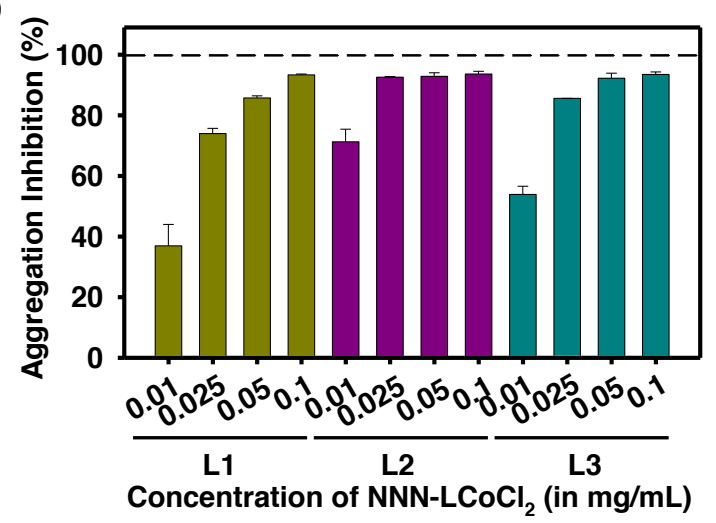

H

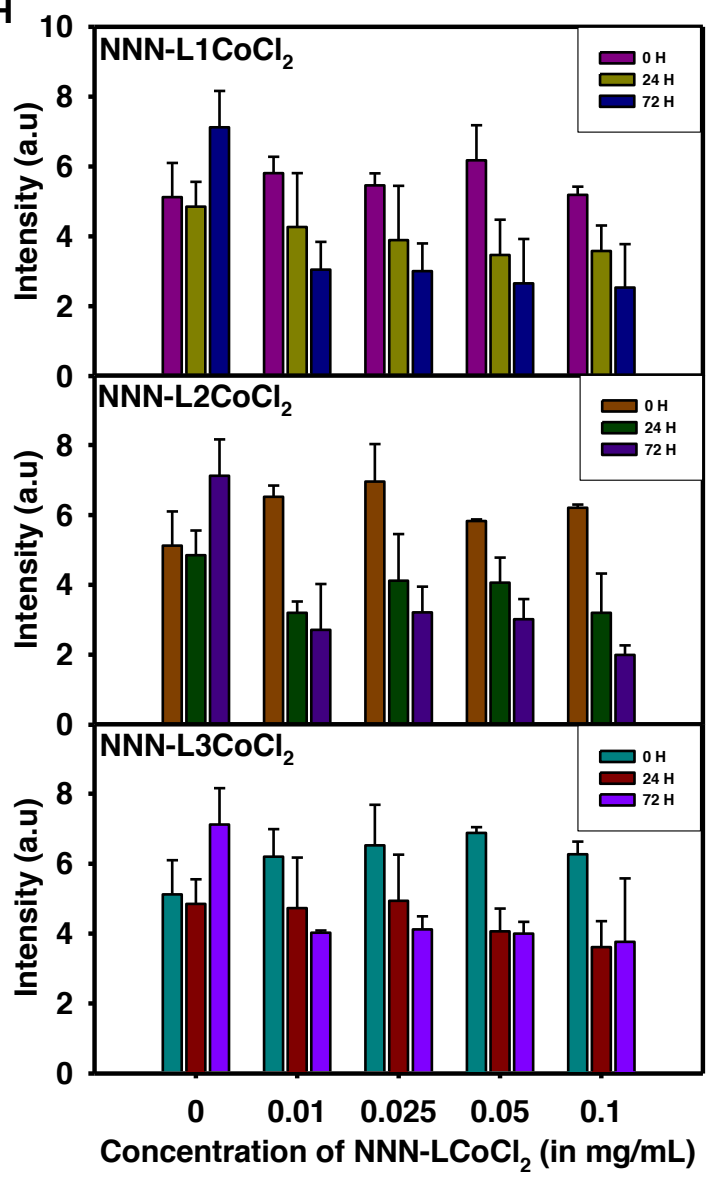




\section{Figure 3}

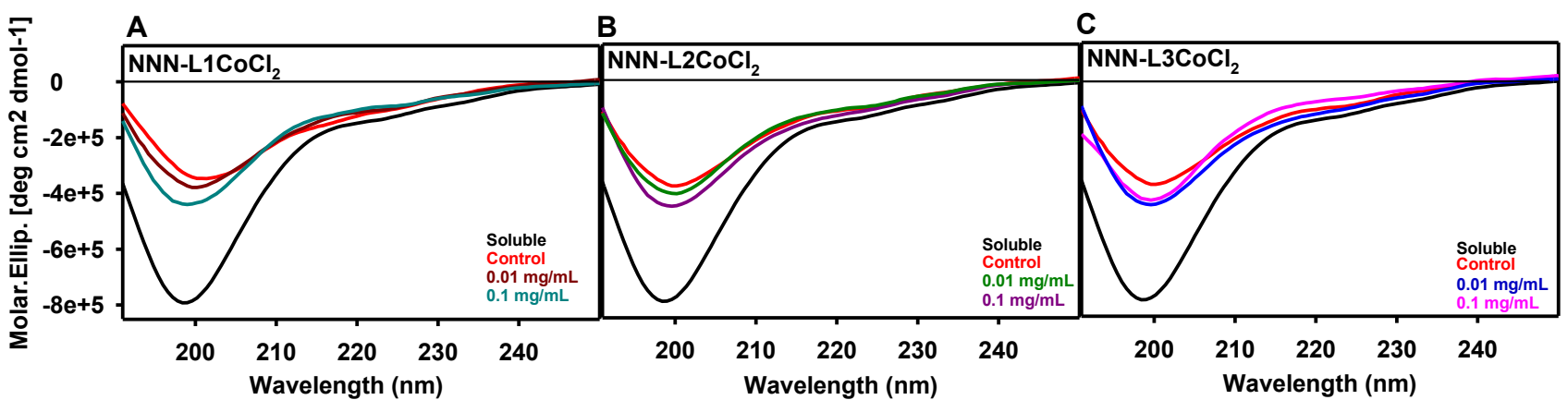

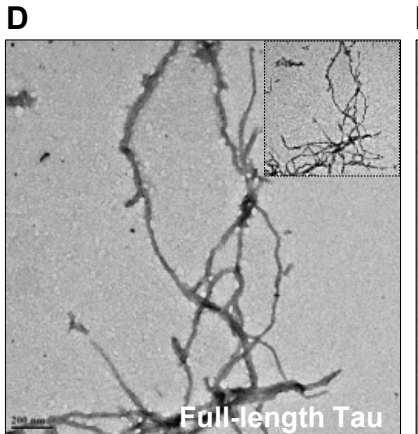

F

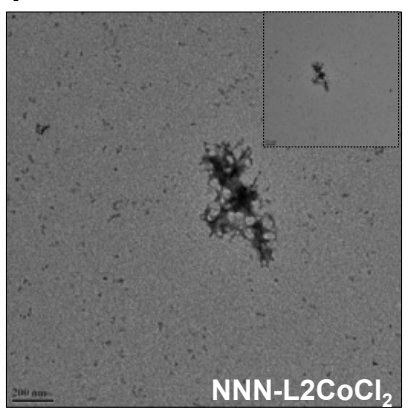

E

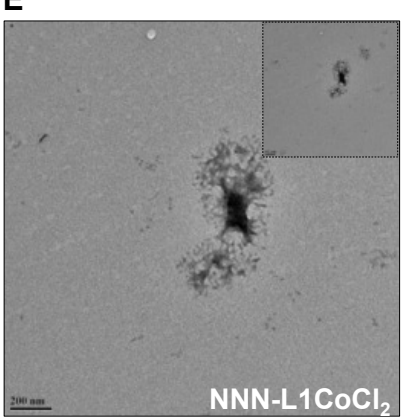

NNN-L1CoCl

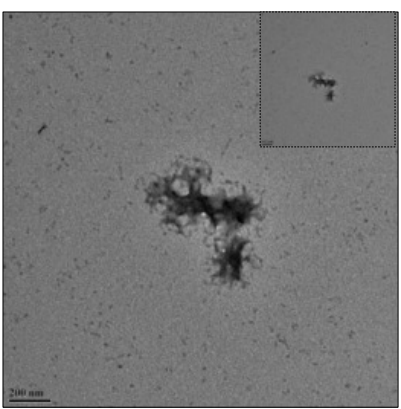

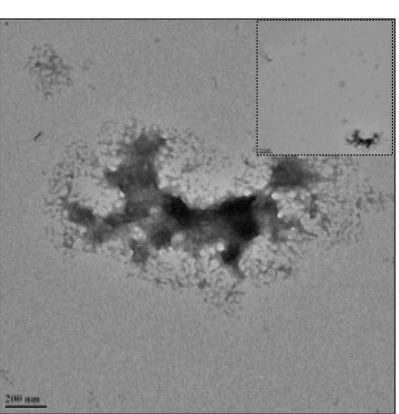

G

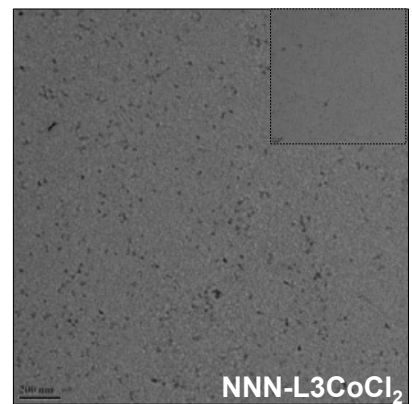

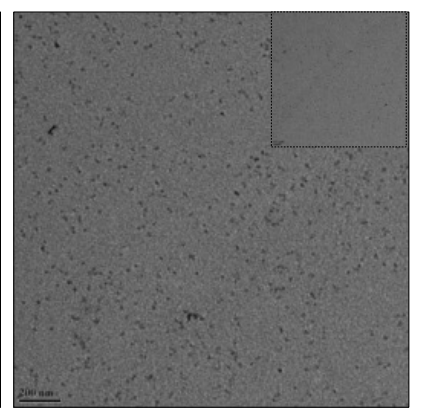




\section{Figure 4}
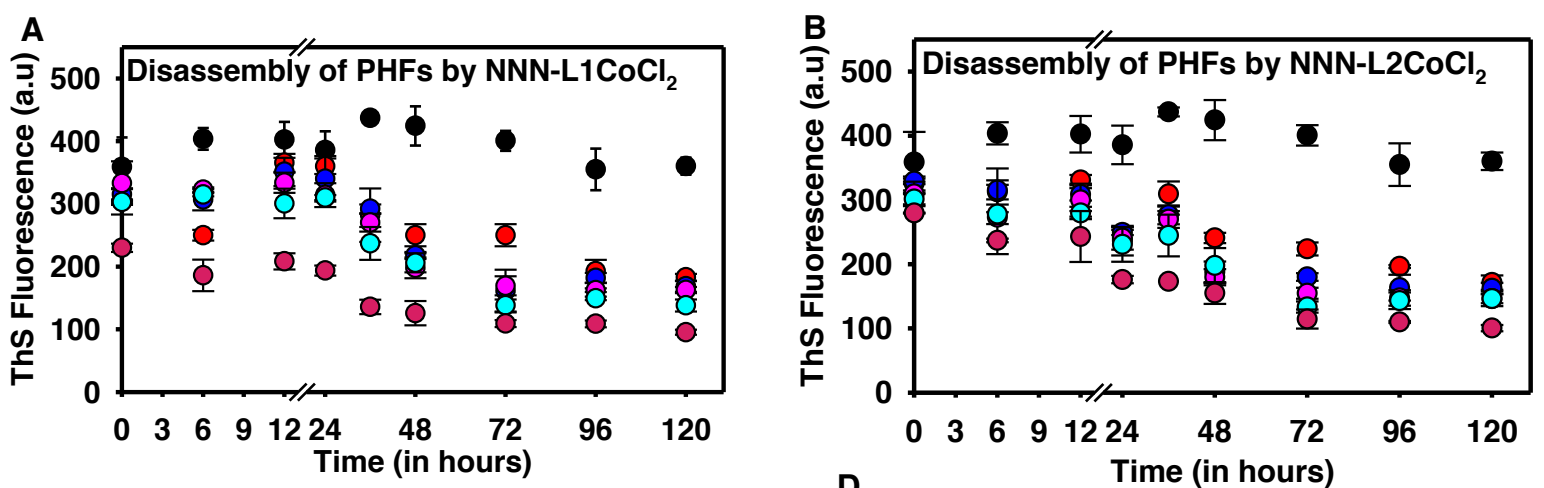

C
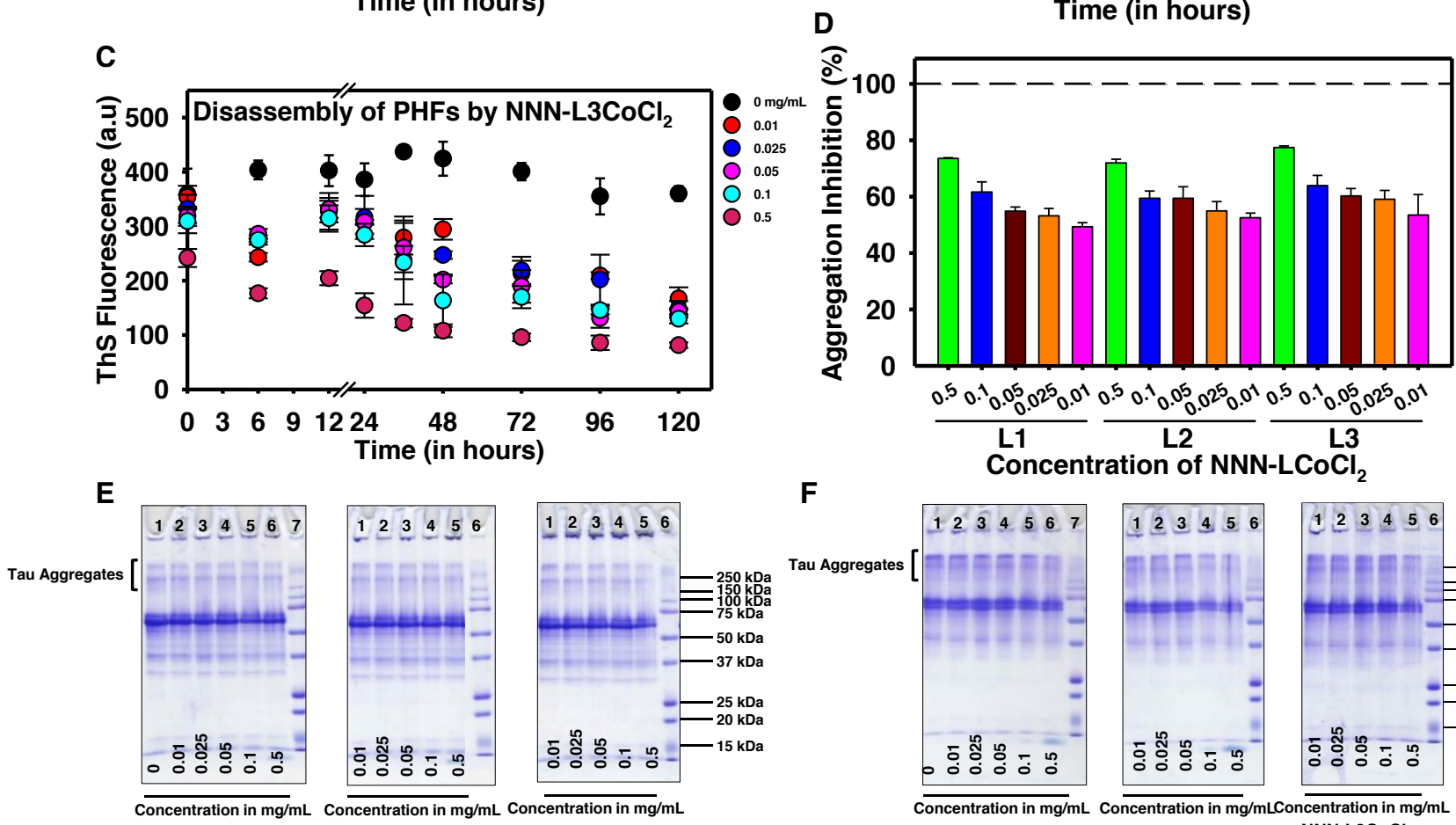

F
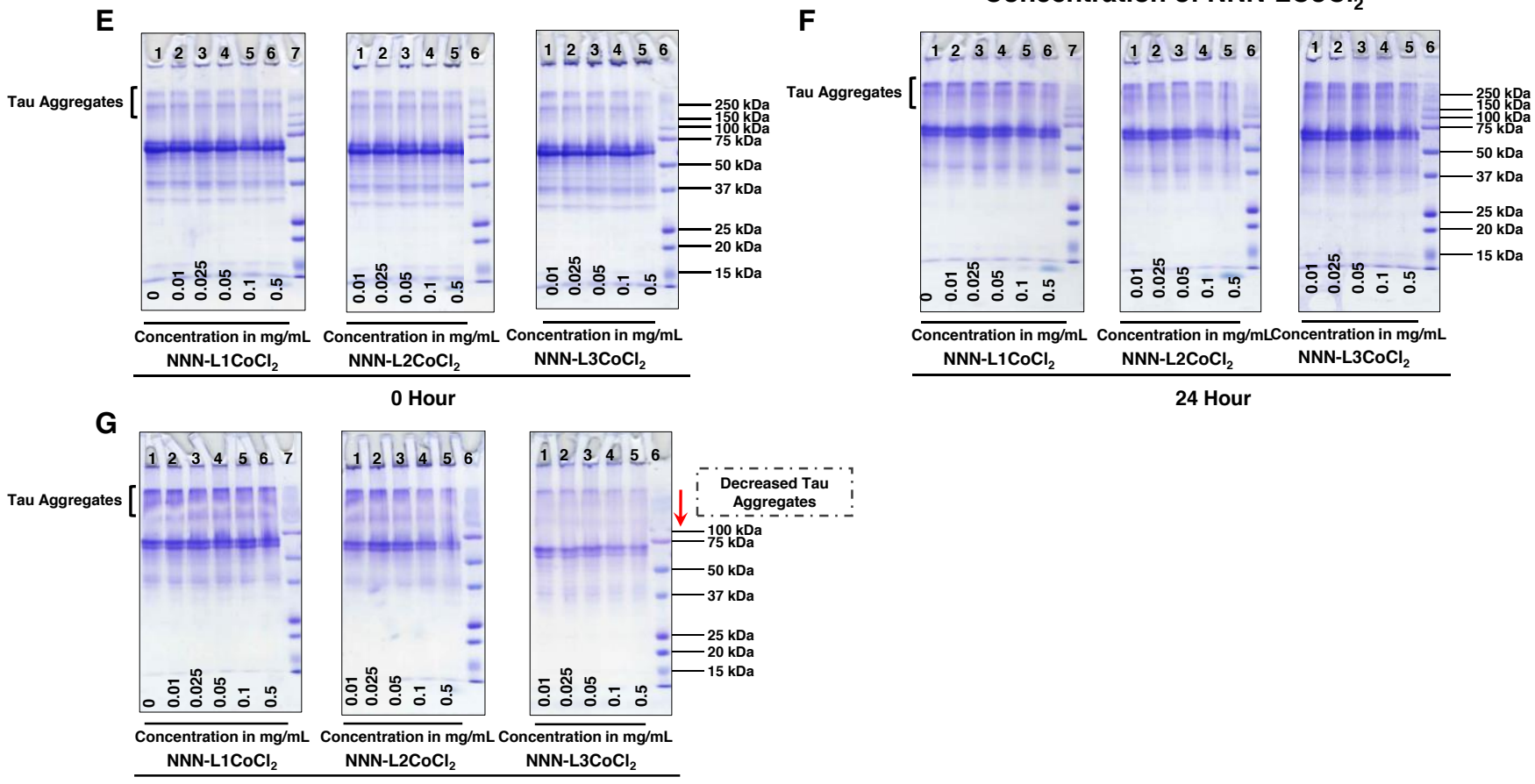

24 Hour

120 Hour 


\section{Figure 5}

Time (min.)

A

B

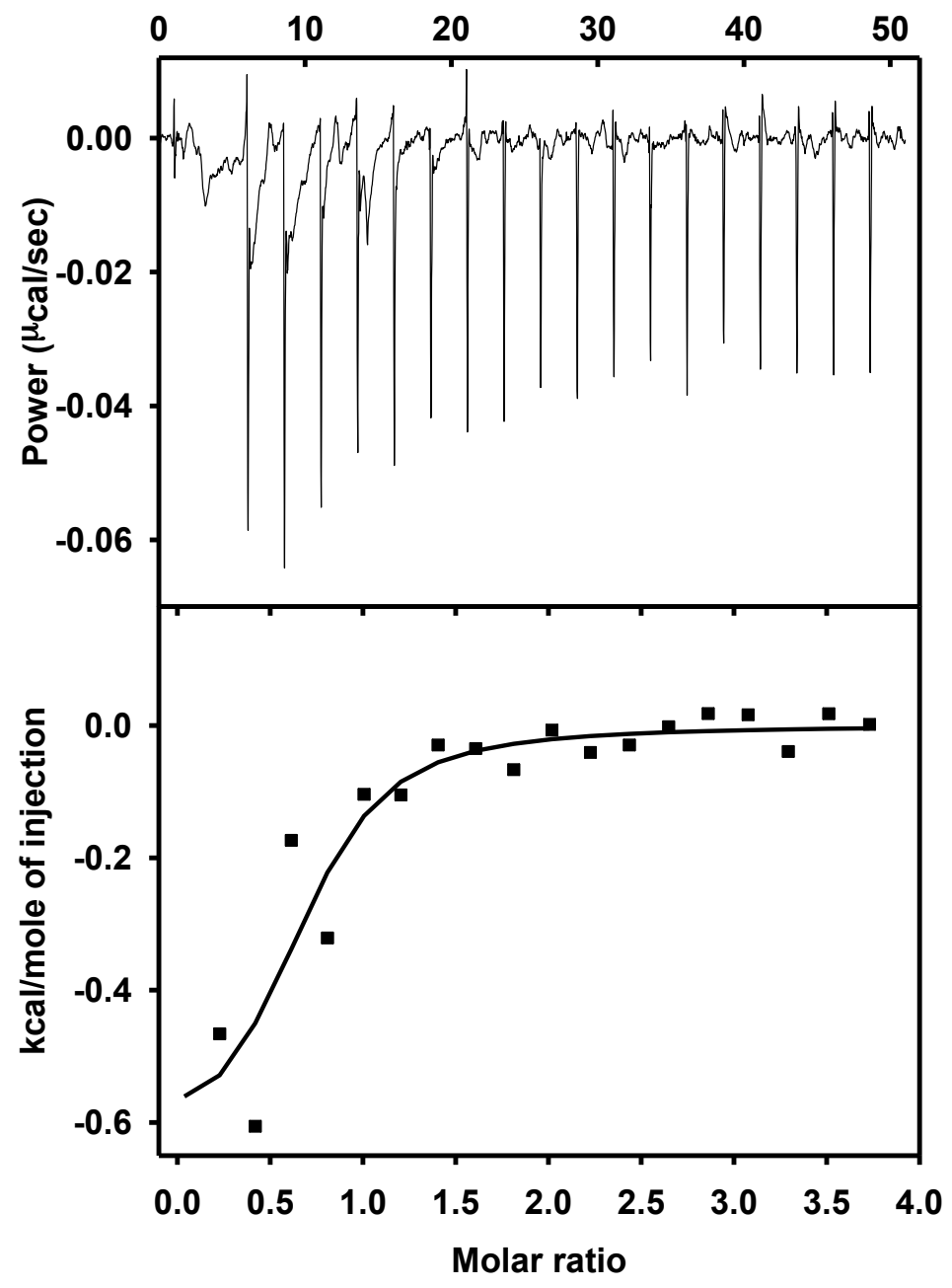




\section{Figure 6}
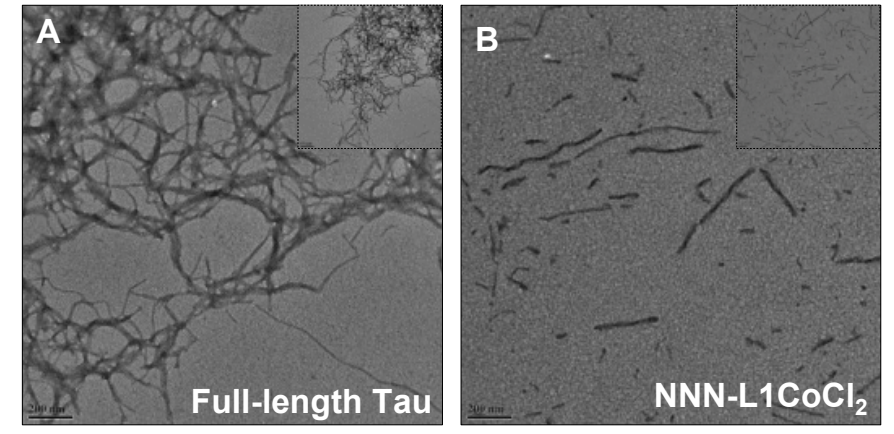

E

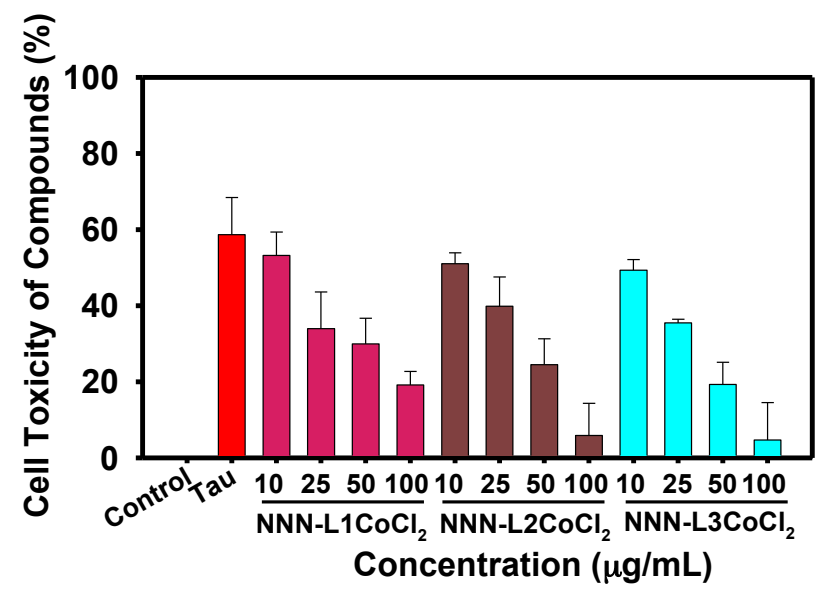

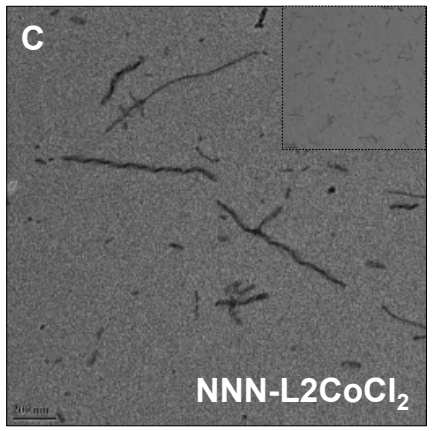

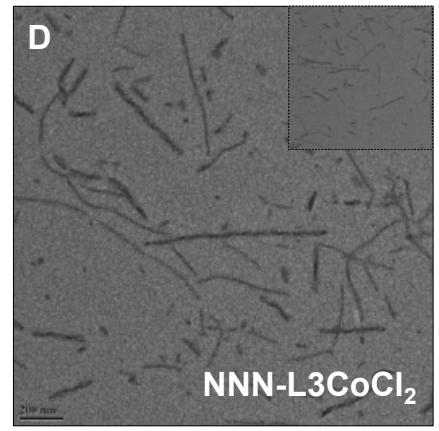

$\mathbf{F}$

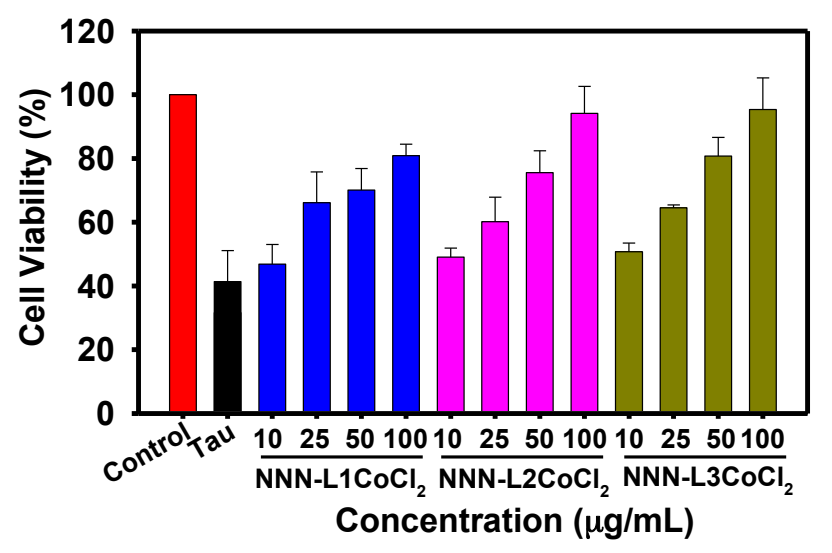

